Glasgow Caledonian

University

University for the Common Good

\title{
An International Urogynecological Association (IUGA)/International Continence Society (ICS) joint report on the terminology for the conservative and nonpharmacological management of female pelvic floor dysfunction
}

Bo, Kari; Frawley, Helena C.; Haylen, Bernard T.; Abramov, Yoram; Almeida, Fernando G. ; Berghmans, Bary; Bortolini, Maria; Dumoulin, Chantale; Gomes, Mario; McClurg, Doreen; Meijlink, Jane; Shelly, Elizabeth; Trabuco, Emanuel ; Walker, Carolina; Wells, Amanda Published in:

Neurourology and Urodynamics

DOI:

$10.1007 / \mathrm{s} 00192-016-3123-4$

Publication date:

2017

Document Version

Author accepted manuscript

Link to publication in ResearchOnline

Citation for published version (Harvard):

Bo, K, Frawley, HC, Haylen, BT, Abramov, Y, Almeida, FG, Berghmans, B, Bortolini, M, Dumoulin, C, Gomes, M, McClurg, D, Meijlink, J, Shelly, E, Trabuco, E, Walker, C \& Wells, A 2017, 'An International Urogynecological Association (IUGA)/International Continence Society (ICS) joint report on the terminology for the conservative and nonpharmacological management of female pelvic floor dysfunction', Neurourology and Urodynamics, vol. 28, no. 2, pp. 191-213. https://doi.org/10.1007/s00192-016-3123-4

Copyright and moral rights for the publications made accessible in the public portal are retained by the authors and/or other copyright owners and it is a condition of accessing publications that users recognise and abide by the legal requirements associated with these rights.

Take down policy

If you believe that this document breaches copyright please view our takedown policy at https://edshare.gcu.ac.uk/id/eprint/5179 for details of how to contact us. 
AN INTERNATIONAL UROGYNECOLOGICAL ASSOCIATION (IUGA) /

INTERNATIONAL CONTINENCE SOCIETY (ICS) JOINT REPORT ON THE

TERMINOLOGY FOR THE CONSERVATIVE AND NON-PHARMACOLOGICAL

MANAGEMENT OF FEMALE PELVIC FLOOR DYSFUNCTION

Kari Bo ${ }^{\wedge}$, Helena Frawley^, Bernard Haylen^*, Yoram Abramov^, Fernando Almeida^,

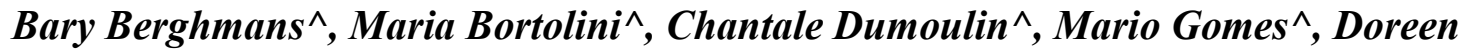
McClurg $^{\wedge}$, Jane Meijlink^, Elizabeth Shelly ${ }^{\wedge}$, Emanuel Trabuco $^{\wedge}$, Caroline Walker $^{\wedge}$, Amanda Wells ${ }^{\wedge}$

Standardization and Terminology Committees IUGA* \& ICS\#, Joint IUGA / ICS Working Group on Conservative Management of Pelvic

Floor Dysfunction^ ${ }^{\wedge}$

Kari Bo, Physiotherapist, exercise scientist Norwegian School of Sport Sciences, Department of Sports Medicine, Oslo. Norway

Helena C. Frawley, Physiotherapist, La Trobe University, Melbourne, Cabrini Health, Melbourne. Australia. Bernard T. Haylen, Urogynaecologist University of New South Wales. Sydney. N.S.W. Australia.

Yoram Abramov, Urogynecologist Technion University, Haifa. Israel.

Fernando Almeida, Urologist Federal University. San Paolo. Brazil

Bary Berghmans, Physiotherapist University of Maastricht, Maastricht. Netherlands.

Maria Bortolini, Urogynecologist Federal University, San Paolo. Brazil.

Chantale Dumoulin, Physiotherapist University of Montreal. Montreal, Quebec. Canada.

Mario Gomes (posthumous), Urologist Centro Hospitalar Porto. Oporto. Portugal.

Doreen McClurg, Physiotherapist/Reader Glasgow Caledonian University. Glasgow. United Kingdom.

Jane Meijlink, Patient Advocate, Naarden. Netherlands.

Elizabeth Shelly, Physiotherapist Moline, Illinois. USA

Emanuel Trabuco, Urogynecologist Mayo Clinic. Minnesota. USA.

Carolina Walker, Physiotherapist FUB Manresa, Autonomous University of Barcelona. Barcelona. Spain.

Amanda Wells, Continence Nurse University of Exeter, Exeter, United Kingdom

Correspondence to:

Professor Kari Bo,

Norwegian School of Sport Sciences, Department of Sports Medicine

Ph: +4723262000; Fax: +4723234220

PO Box 4014, Ullevål Stadion, 0806 Oslo, Norway e-mail: $\quad$ Kari.bo@nih.no 
Disclaimer: any products/companies referred to in this document are not necessarily recommended or endorsed by the ICS.

WORDS (Introduction-Section 5) 11,354

FIGURES 9

Financial Disclaimers/Conflict of Interest:Kari Bo: No disclosures

Helena Frawley: No disclosures

Bernard Haylen: No disclosures

Yoram Abramov: No disclosures

Fernando Almeida: No disclosures

Bary Berghmans: No disclosures

Maria Augusta Bortolini: No disclosures

Chantale Dumoulin: No disclosures

Doreen McClurg: No disclosures

Jane Meijlink: No disclosures

Elizabeth Shelly: Consultant Analytica

Emanuel Trabuco: No disclosures

Carolina Walker: No disclosures

Amanda Wells: Consultant ARC health service

Each authors' contribution to the Manuscript:

K Bo: $\quad$ Project development, manuscript writing

H Frawley: Project development, manuscript writing

B Haylen: Project development, manuscript writing

Y Abramov: Manuscript writing

F Almeida: Manuscript writing

B Berghmans: Manuscript writing

MA Bortolini: Manuscript writing

C Dumoulin: Manuscript writing

J Meijlink: Manuscript writing

E Shelly: Manuscript writing

E Trabuco: Manuscript writing

C Walker: Manuscript writing

A Wells: Manuscript writing 


\section{ABSTRACT}

Introduction: There has been an increasing need for the terminology for the conservative management of female pelvic floor dysfunction to be collated in a clinically-based consensus report.

Methods: This Report combines the input of members and elected nominees of the Standardization and Terminology Committees of two International Organizations, the International Urogynecological Association (IUGA) and the International Continence Society (ICS), assisted at intervals by many external referees. An extensive process of nine rounds of internal and external review was developed to exhaustively examine each definition, with decision-making by collective opinion (consensus). Before opening up for comments on the webpages of ICS and IUGA, five experts from physiotherapy, neurology, urology, urogynecology and nursing were invited to comment on the paper.

Results: A Terminology Report for the conservative management of female pelvic floor dysfunction, encompassing over 200 separate definitions, has been developed. It is clinicallybased with the most common symptoms, signs, assessments, diagnoses and treatments defined. Clarity and user-friendliness have been key aims to make it interpretable by practitioners and trainees in all the different specialty groups involved in female pelvic floor dysfunction.

Ongoing review is not only anticipated but will be required to keep the document updated and as widely acceptable as possible.

Conclusion: A consensus-based terminology report for the conservative management of female pelvic floor dysfunction has been produced aimed at being a significant aid to clinical practice and a stimulus for research.

KEYWORDS: Consensus, Conservative Management, Pelvic Floor Dysfunction, 
Terminology, Female

\section{Brief Summary:}

This consensus-based terminology report for the conservative management of female pelvic floor dysfunction aims to provide clarity to description of clinical practice and research. 
INTRODUCTION

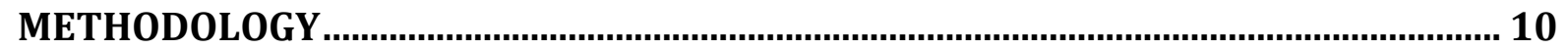

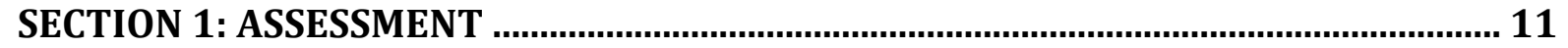

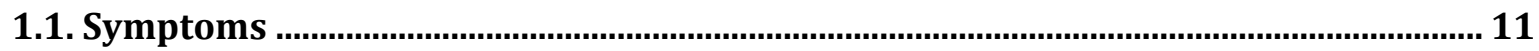

1.1.A. Existing (defined) Symptoms ........................................................................................ 11

1.1.B. Lower Urinary Tract Pain and/or Other Pelvic Pain .............................................................. 11

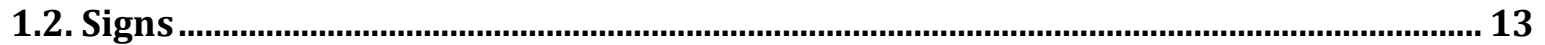

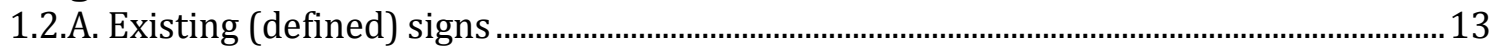

1.2.B. Pelvic Floor Muscle Function Signs ……………................................................................. 15

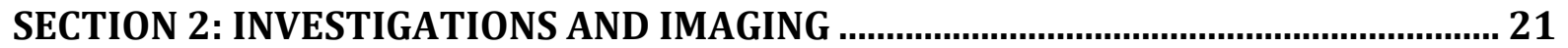

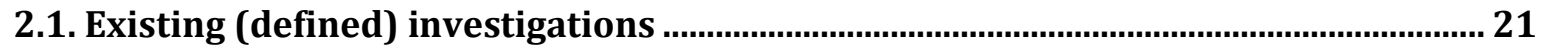

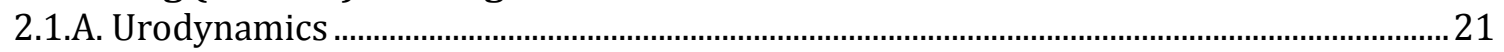

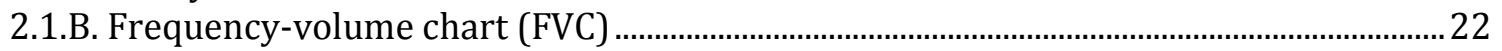

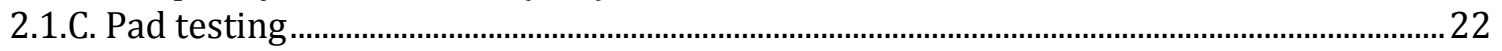

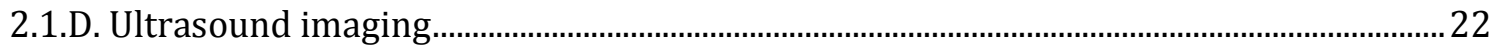

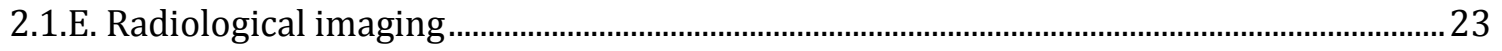

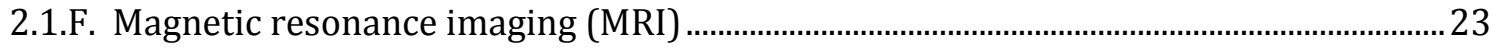

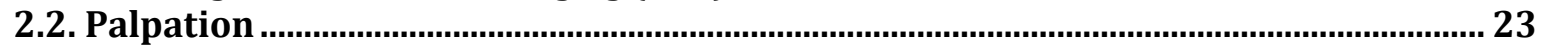

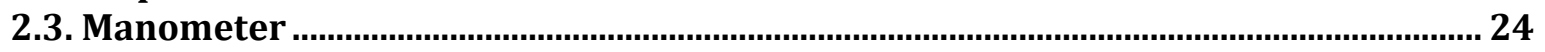

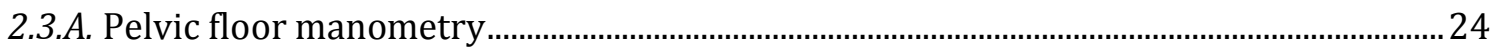

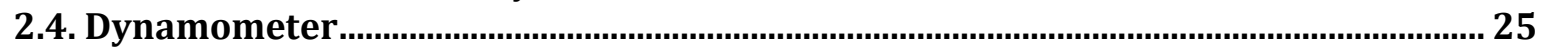

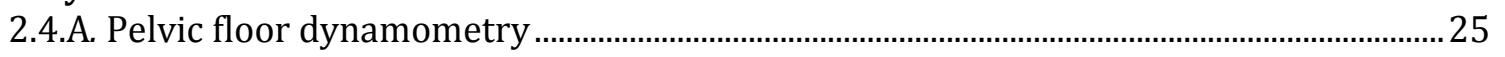

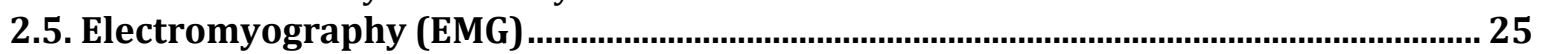

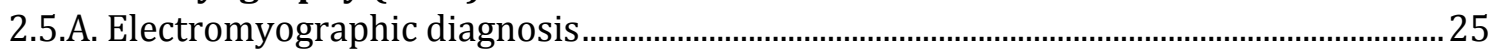

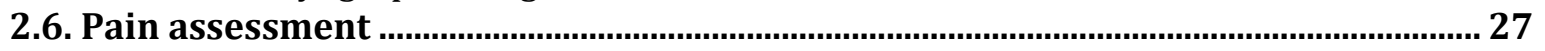

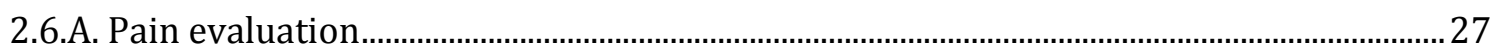

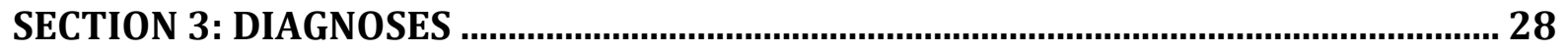

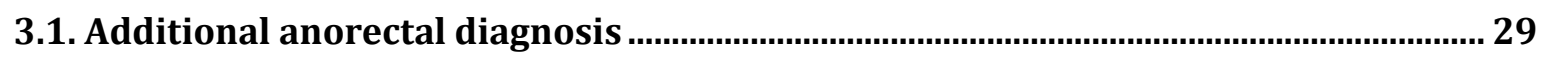

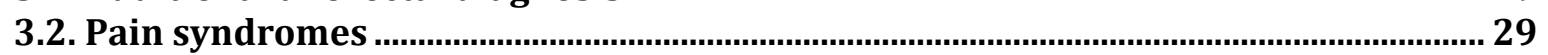

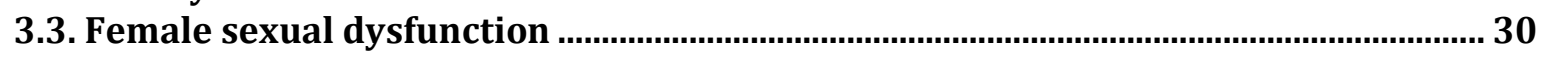

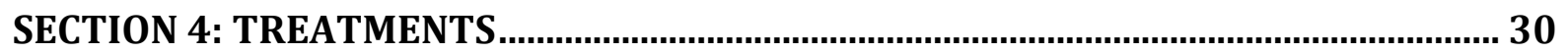

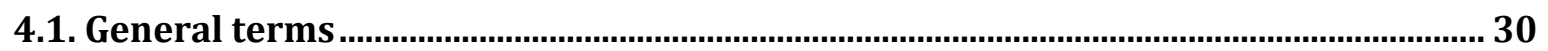

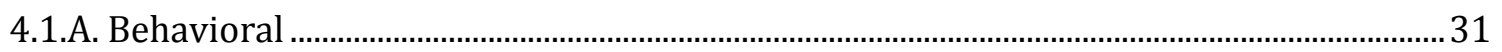

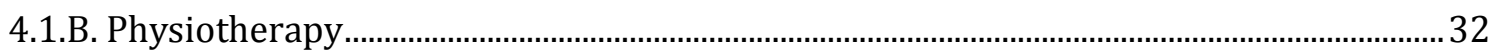

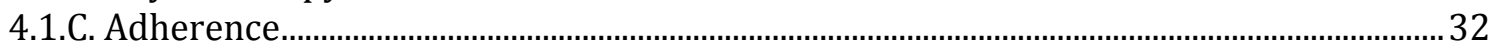

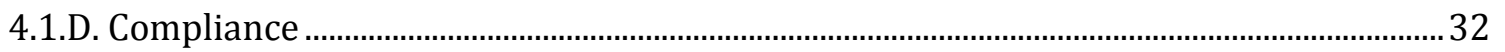

4.1.E. Combination therapy (also known as polytherapy, multimodal therapy or combined

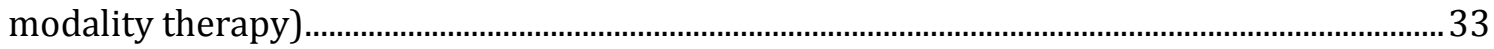

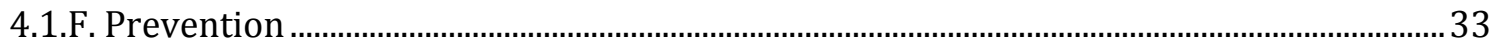

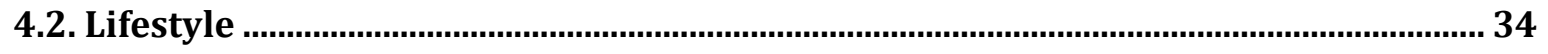

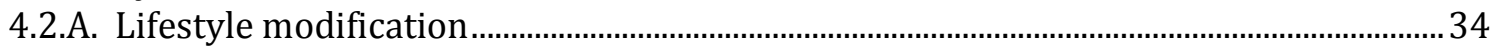

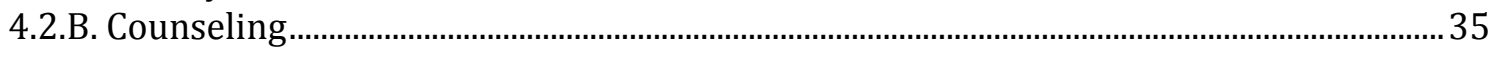

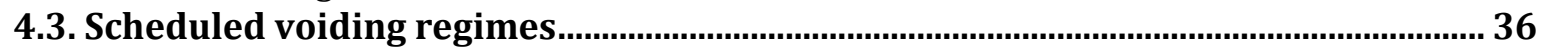

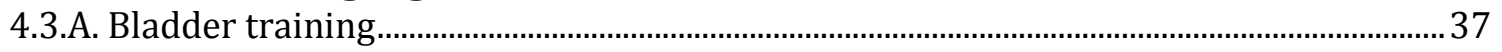

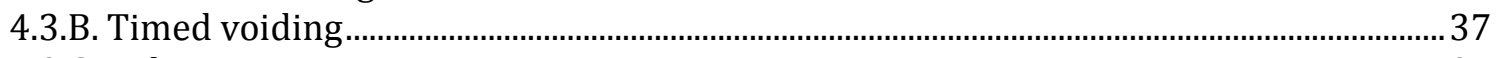

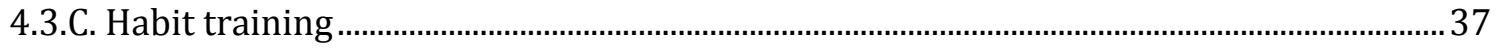

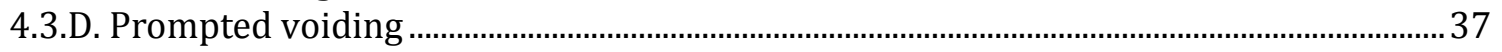

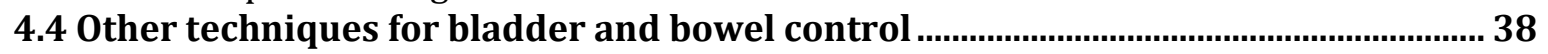

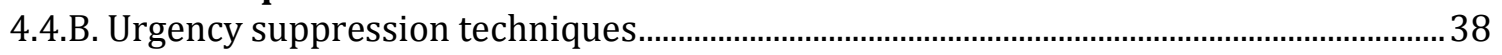




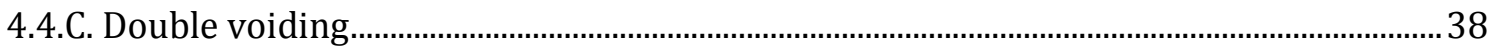

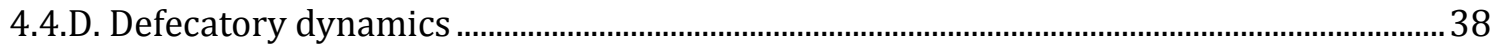

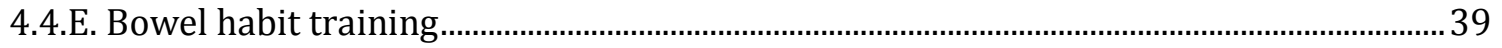

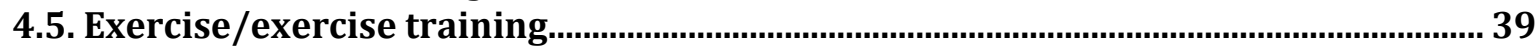

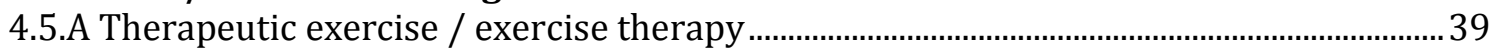

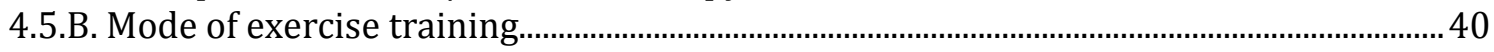

4.5.C. Dose-response issues related to exercise training …………................................................. 43

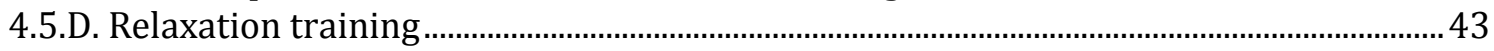

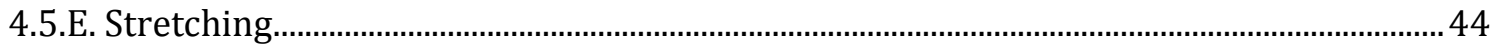

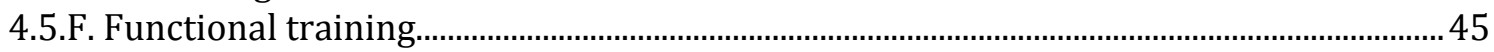

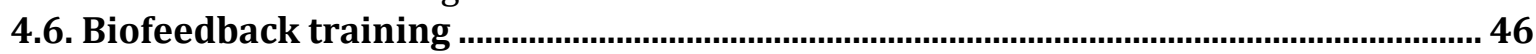

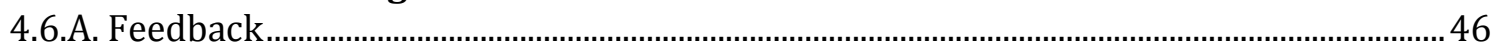

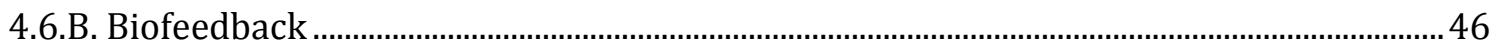

4.6.C. EMG Biofeedback Unit Instrumentation .............................................................................. 47

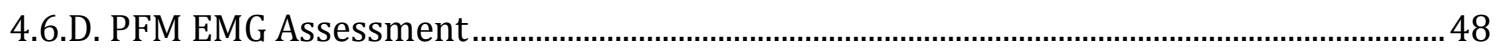

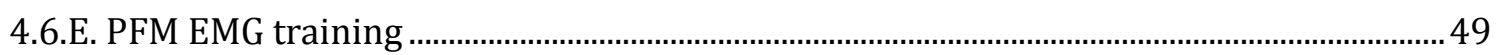

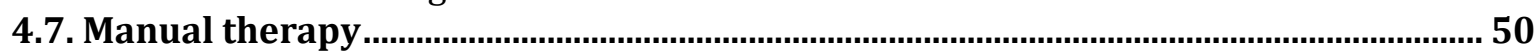

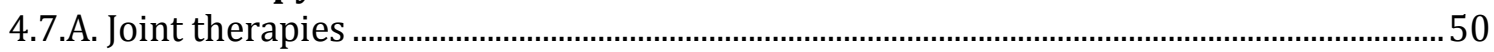

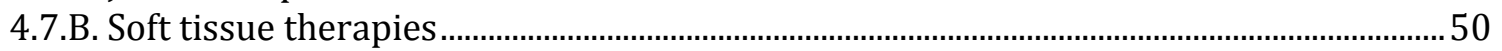

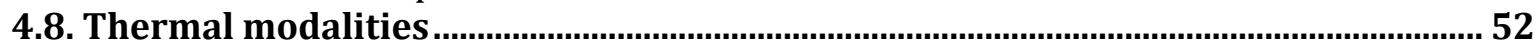

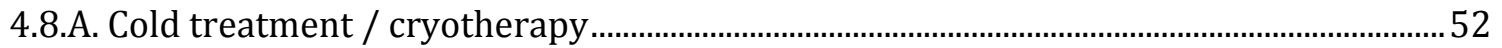

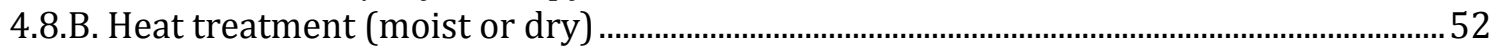

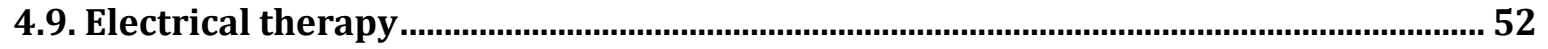

4.9.A. Electrical muscle stimulation (EMS) (also known as neuromuscular electrical

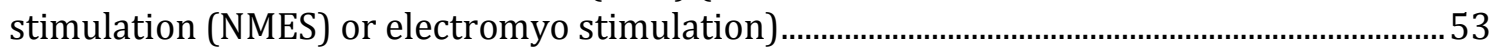

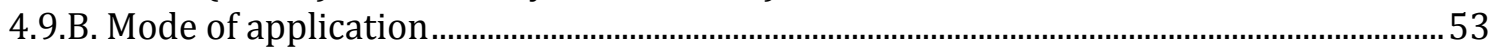

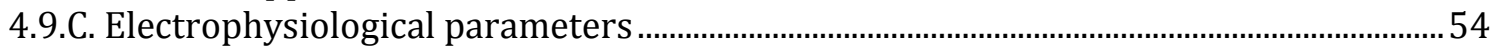

4.9.D. Neuromuscular Electrical stimulation parameters …………………………………….... 56

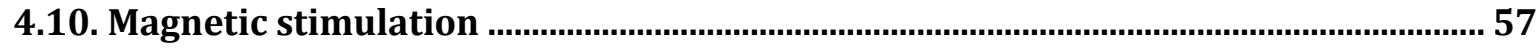

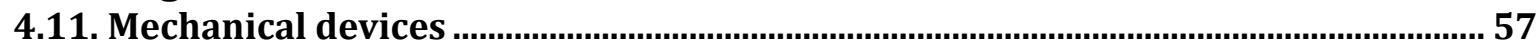

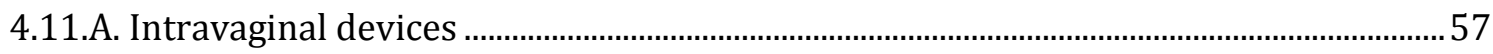

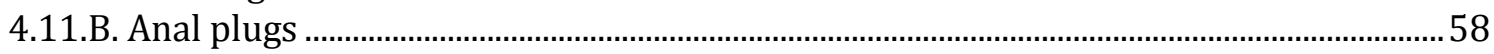

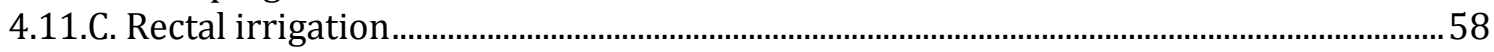

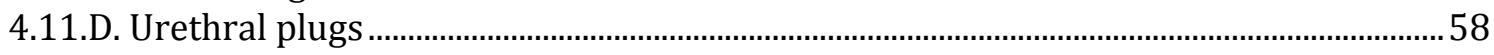

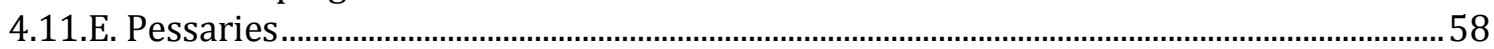

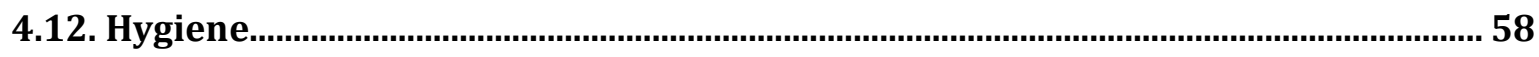

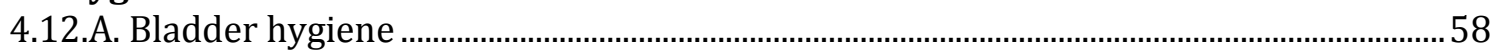

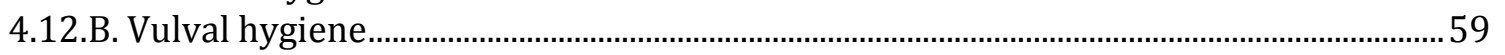

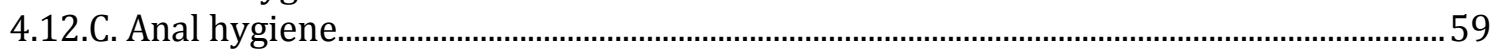

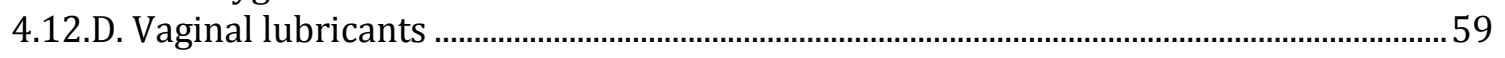

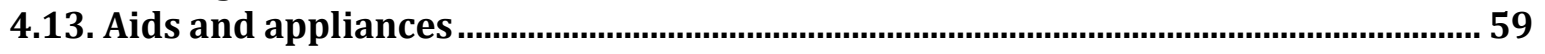

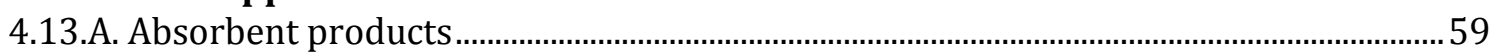

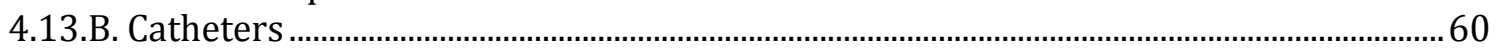

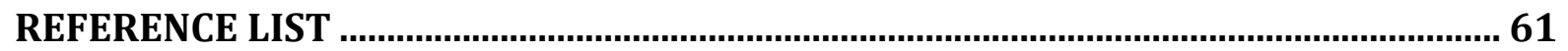




\section{INTRODUCTION}

There is currently no single document addressing the conservative management of female pelvic floor dysfunction in a comprehensive way. The report is based on, and follows on from, the terminology proposed by the International Continence Society (ICS) Standardization of Terminology of Lower Urinary Tract Function [1]. The Standardization of Terminology of Pelvic Floor Muscle Function and Dysfunction: Report from the pelvic floor clinical assessment group of the International Continence Society [2] and the International Urogynecological Association (IUGA)/International Continence Society (ICS) joint report on the terminology for female pelvic floor dysfunction [3].

The terminology in current use related to conservative management generally lacks uniformity, often because different disciplines use their own terminology. The range of terms in use can lead to uncertainty, confusion and unintended ambiguity. It hampers the ability to build a body of literature concerning conservative interventions, e.g. the terms "behavioral therapy", "lifestyle intervention", "conservative treatment", "non-surgical treatment", "physiotherapy", "biofeedback", and "pelvic floor muscle exercise" are often used interchangeably and, at times, incorrectly to describe both the same and different interventions. A more standardized terminology would aid inter-disciplinary communication and understanding.

Existing published reports address some of the aspects of this topic, but there are some areas currently lacking in standardisation of terminology, e.g. Messelink et al [2] and Haylen et al [3] refer to evaluation and diagnostic terminology, but not treatment terminology. 
There is a need for a more extensive description of management of pelvic floor and pelvic floor muscle (PFM) dysfunction than is currently provided in existing terminology reports. With the development of the evidence-base for conservative therapies in the management of pelvic floor dysfunction (PFD), especially treatment of conditions such as incontinence and pelvic organ prolapse, terminology linked with these managements has evolved but with regional and discipline variations. A consensus on currently accepted terminology is required. Elements in the title of the document need to be defined:

Conservative: is restricted to non-surgical and non-pharmacological approaches.

Management: will include the following aspects: a) Assessment: including history and physical examination and investigations; b) diagnosis, c) prevention and d) treatment of pelvic floor dysfunction.

Pelvic floor: structures located within the bony pelvis: urogenital and anorectal viscera, pelvic floor muscles and their connective tissues, and nerves and blood vessels.

\section{Pelvic floor dysfunction:}

Following on from Messelink et al report from the pelvic floor clinical assessment group of the ICS [2], this report will focus on terminology of management of pelvic floor function and dysfunction including bladder and bowel dysfunction, POP, sexual dysfunction and pelvic pain [4]. Terminology regarding pelvic pain and anorectal dysfunction related to PFM dysfunction will align with the current working groups on chronic pelvic pain and anorectal dysfunction. Terminology will include symptoms, signs and investigations (expanding on the Messelink et al paper [2]; diagnoses of PFM-related conditions (avoiding duplication with 
Haylen et al [3]); prevention and treatment (including new therapies, e.g. exercise and adjunctive therapies including equipment, and lifestyle modifications - not covered by Messelink et al [2] or Haylen et al [3].

\section{Additional descriptions related to the terms used in this manuscript}

\section{Clinicians/Practitioners}

Conservative management of PFD may be provided by clinicians or practitioners of different disciplines, commonly physiotherapists / physical therapists, nurses, midwifes and medical doctors. However, other professions e.g. fitness instructors and personal trainers may also have a role in both education, health promotion and prevention of PFD. Terminology related to the accepted names of professions and the different types of therapies must be specified and distinguished (e.g. 'physiotherapy' as a management provided by a registered physiotherapist, distinct from 'conservative therapy' and 'exercises' / 'biofeedback' which may be provided by any clinician). The emphasis in this document will be on management commonly undertaken by clinicians practicing conservative management.

\section{Multi-disciplinary approach}

Relating to, or involving, two or more disciplines that are usually considered distinct [5], e.g. physical therapy, urology, gynecology.

Gender. With the increasing specificity and complexity of female diagnosis and management it can be argued that a gender specific report is needed. However many of the terms defined in this report are not gender specific and will be the same for males e.g. PFM training and electrical stimulation. This report does not exclude an additional future report on male pelvic floor dysfunction. 


\section{METHODOLOGY}

All working group members were asked to provide terms that they knew existed in the area. After the first "brainstorming activity", all terms were listed and grouped according to introduction, symptoms, signs, examination methods, investigations, diagnosis, prevention and treatment. All members were given the text to add more terms. Additional searching for omitted terms in existing terminology papers of the ICS and IUGA, Cochrane reviews and the 2013 ICI document [6] were undertaken. Existing definitions of established terms from general medicine $[7,8]$, physiotherapy [5] and exercise science were used where available. Only in situations where there was no existing terminology, were new definitions introduced. We have not referred to or described the responsiveness, reliability and validity of the measurement methods of symptoms, signs and evaluations, nor the evidence for treatment efficacy of any of the therapies defined.

Agreement on the definitions was reached by consensus. Wherever possible, evidence based principles were followed. However, this was a challenge in conservative management as there are many suggested therapies that do not have proven effectiveness [9,10]. Discussion meetings with representatives of IUGA and ICS were held at the following annual meetings: IUGA Brisbane 2012, ICS Beijing 2012, IUGA Dublin 2013, ICS Barcelona 2013, IUGAAUGS Washington DC 2014, IUGA Nice 2015.

It is recommended that acknowledgment of these standards in written publications related to conservative management of female pelvic floor dysfunction is read as follows: "Methods, definitions and units conform to the standards jointly recommended by the IUGA-ICS joint report on the terminology for the conservative and non-pharmacological management of female pelvic floor dysfunction, except where specifically noted". 


\section{SECTION 1: ASSESSMENT}

\subsection{Symptoms}

Symptom: Any morbid phenomenon or departure from the normal in structure, function or sensation, experienced by the woman and indicative of disease or a health problem.

Symptoms are either volunteered by, or elicited from the individual, or may be described by the individual's caregiver [3].

\subsection{A. Existing (defined) Symptoms}

(i) Urinary incontinence symptoms [3]

(ii) Bladder storage symptoms [3]

(iii) Sensory symptoms [3]

(iv) Voiding and postmicturition symptoms [3]

(v) Pelvic organ prolapse (POP) symptoms [3]

(vi) Symptoms of sexual dysfunction [3]

(vii) Symptoms of anorectal dysfunction ${ }^{1}[3]$

(viii) Lower Urinary Tract Infection [3]

\subsection{B. Lower Urinary Tract Pain and/or Other Pelvic Pain ${ }^{2}$}

(i) Pain (in general): “An unpleasant sensory and emotional experience associated with actual or potential tissue damage, or described in terms of such damage" [13].

\footnotetext{
${ }^{1}$ Terminology for Female Anorectal Dysfunction [11].

${ }^{2}$ Comprehensive definition of these terms is covered by Doggweiler et al [12].
} 
(ii) Tenderness: sensation of discomfort with or without pain; discomfort elicited through palpation, indicates unusual sensitivity to pressure or touch [14].

(iii) Acute pain: pain related to acute trauma, infection or other well-defined disease processes or conditions.

(iv) Chronic pain: Persistent or continuous / recurrent pain for at least 6 months. If non-acute and central sensitization pain mechanisms are well documented, then the pain may be regarded as chronic, irrespective of the time period $[15,16]$.

(v) Myalgia: muscle pain. Pelvic floor myalgia (a symptom) may be present with or without a change in PFM tone (a sign) ${ }^{3}$.

(vi) Myofascial pain: pain caused by the presence of trigger points within muscles or their $\operatorname{fascia}^{4}[18]$

\footnotetext{
${ }^{3}$ Symptoms of pelvic floor myalgia should be described in terms of location, quality, intensity, pattern, duration, frequency, moderating factors and associated symptoms. Pain details may include:

a. whether pain is present at rest or mechanical in nature (related to muscle contraction or relaxation or body posture) and / or altered with change of posture (lying to sitting, sitting to standing) or movement (bending, walking, sexual activity).

b. may be uni- or bilateral in nature.

c. may be accompanied by bladder or bowel dysfunction, vulvodynia or dyspareunia (superficial/deep).
} 


\subsection{Signs}

Sign: Any abnormality indicative of disease or a health problem, discoverable on examination of the patient; an objective indication of disease or a health problem [1].

\subsection{A. Existing (defined) signs}

(i) Urinary incontinence signs: [3]

a. Urinary incontinence [3]

b. Stress (urinary) incontinence [3]

c. Urgency (urinary) incontinence [3]

d. Extraurethral incontinence [3]

e. Stress incontinence on prolapse reduction (occult or latent stress incontinence) [3]

(ii) Pelvic organ prolapse signs: [3]

a. Uterine/cervical prolapse [3]

b. Vaginal vault (cuff scar) prolapse [3]

c. Anterior vaginal wall prolapse [3]

d. Posterior vaginal wall prolapse [3]

(iii) Other pelvic examinations/signs [3]:

a. Vulval abnormalities [3]

b. Urethral mucosal prolapse [3]

c. Urethral caruncle [3]

\footnotetext{
${ }^{4}$ The evidence for the existence of trigger points is debated [17].
} 


\section{d. Urethral diverticulum [3]}

e. Total vaginal length (TVL): the distance from the posterior fornix to hymen [19].

f. Valsalva maneuver: the action of attempting to exhale with the nostrils and mouth, or glottis closed [7]. Valsalva is usually performed with digital closure of the nose as in trying to equalize pressure in a plane. Straining / bearing down may have a similar meaning as Valsalva, however in practice straining/bearing down may be interpreted to mean pushing downwards and trying to relax the pelvic floor, as in defecating.

\section{g. Bimanual pelvic examination [3]}

h. Perineal elevation: inward (ventro-cephalad) movement of the vulva, perineum, and anus during e.g. PFM contraction.

i. Perineal descent: excessive dorso-caudal movement of the vulva, perineum, and anus e.g during cough, Valsalva or straining [20,3].

j. Trophic: promoting cellular growth, differentiation and survival [8]. This is the normal status of an organ, tissue or cell in regards to nutrition, size, number, form and function. A trophic urogenital tract is usually well-estrogenized.

k. Atrophic: decrease from previous normal size of the body or a part, cell, organ, or tissue. An organ or body part's cells may be reduced in number, size or both. Atrophy of some cells and organs is normal at certain points in the life cycle. Other causes include malnutrition, disease, disuse, injury, and hormone over- or underproduction ${ }^{5}[8]$.

\section{(iv) Anal signs [11]}

\section{(v) Abdominal signs}

\footnotetext{
${ }^{5}$ Atrophy of urogenital tract is normal at certain points in the life cycle, mainly caused by aging and hypoestrogenism $[8,21]$.
} 
a. Bladder fullness/retention: abdominal palpation or suprapubic percussion may indicate a full bladder, however in overweight patients this may not be easily detected.

b. Pelvic bone irregularities: indication of previous fracture or sacral agenesis.

\section{(vi) Neurological signs}

Abnormalities of the nervous system detected by physical examination which reflect an underlying neurological disease or injury. Examples of abnormal signs may include altered sensation, muscle tone or reflexes. If present, the patient should be referred for a full neurological examination.

\subsection{B. Pelvic Floor Muscle Function Signs}

(i) Normal pelvic floor muscles: have a level of constant resting tone (except just before and during voiding and defecation), symmetry and ability to voluntarily and involuntarily contract and relax.

(ii) Normal pelvic floor muscle contractile function: a constriction and inward (ventrocephalad) movement of the pelvic openings. Normal, well-functioning pelvic floor muscles may demonstrate some (controlled or limited) downward dorsal perineal movement in response to increased intra-abdominal pressure in the absence of incontinence or pelvic organ prolapse.

(iii) Muscle tone: state of the muscle, usually defined by its resting tension, clinically determined by resistance to passive movement [22-24]. Muscle tone has two components: 1) the contractile component, created by a low-frequency activation of a small number of motor units; 2) the viscoelastic component, which is independent of neural activity and reflects the 
passive physical properties of the elastic tension of the muscle fiber elements and the osmotic pressure of cells ${ }^{6}[22]$.

a. Hypertonicity: an increase in muscle tone related to the contractile or viscoelastic components that can be associated with either elevated contractile activity and / or passive stiffness in the muscle $[23,25]$. The terms neurogenic hypertoncity and non-neurogenic hypertonicity are recommended to describe the diagnosis and inform management.

b. Hypotonicity: a decrease in muscle tone related to the contractile or viscoelastic components that can be associated with either reduced contractile activity and / or passive stiffness in the muscle. The terms neurogenic hypotonicity and non-neurogenic hypotonicity are recommended to describe the diagnosis and inform management ${ }^{7}$.

\footnotetext{
${ }^{6}$ Muscle tone is evaluated clinically as the resistance provided by a muscle when a pressure / deformation or a stretch is applied to it [22-24]. Muscle tone may be altered in the presence or absence of pain. There is no single accepted or standardised way to measure muscle tone, and there are no normative values.

${ }^{7}$ The terms hyper-and hypotonicity are commonly used in neurology and muscle physiology. Messelink et al [2] introduced the terms overactivity and underactivity related to pelvic floor muscles. These terms are not defined with cut-off points, nor are based on comparison with normal populations. As activity can only relate to the active (i.e. contractile) portion of muscle tone, activity cannot be used interchangeably with muscle tone, unless it can be shown that the active component of the muscle is altered. If increased (over) or decreased (under) activity in the PFM can be demonstrated by EMG or another measure, then these terms may be used appropriately.
} 
(iv) Stiffness: resistance to deformation [26]. Passive elastic stiffness is defined as the ratio of the change in the passive resistance or passive force $(\Delta F)$ to the change in the length displacement $(\Delta L)$ or $\Delta F / \Delta L$ [27]. The term should only be used if stiffness is measured quantitatively such as with instruments like dynamometry or myotonometry.

(v) Tension: may have a similar meaning to tone and stiffness. Muscle tension can be increased or decreased due to exogenous factors such as the amount of pressure applied and endogenous factors such as thickness/ cross sectional area of the muscle itself, fluid present within the muscle (swelling, inflammation), position (e.g. standing versus sitting) or increased neural activity.

(vi) Spasm: persistent contraction of striated muscle that cannot be released voluntarily. If the contraction is painful, this is usually described as a cramp. Occurs at irregular intervals with variable frequency and extent [28]. Spasm over days or weeks may lead to a contracture.

(vii) Contracture: an involuntary shortening of a muscle. Clinically, a muscle cramp and contracture may appear similar, however contractures are electrically silent [29].

(viii) Cramp: a painful involuntary muscle contraction that occurs suddenly and can be temporarily debilitating. Pain is intense and localised. It tends to occur when the muscle is in the shortened position and contracting, is generated by motor units, and displays a high firing rate $(20-150 \mathrm{~Hz})^{8}[29]$.

\footnotetext{
${ }^{8}$ Muscle cramp either during or immediately after exercise is commonly referred to as "exercise associated muscle cramping" [30], however cramps are not specific to exercise.
} 
(ix) Fasciculation: a single, spontaneous, involuntary discharge of an individual motor unit. The source generator is the motor unit or its axon, prior to its terminal branches. Fasciculations display an irregular firing pattern of low frequency $(0.1-10 \mathrm{~Hz})[29,5]$. Clinically, fasciculations are recognised as individual brief twitches. They may occur at rest or after muscle contraction and may last several minutes.

(x) Tender point: tenderness to palpation at soft tissue body sites [22].

(xi) Trigger point (TrP): a tender, taut band of muscle that can be painful spontaneously or when stimulated [31]. The taut band is electrically silent ${ }^{9}$.

(xii) Pelvic floor muscle dyssynergia [2]: incoordination of the pelvic floor muscles and another muscle group during a functional activity, for example, the pelvic floor muscles may not relax appropriately during micturition or defecation.

(xiii) Non-functioning pelvic floor muscles (modified from Messelink et al.) [2]: a situation in which there is no pelvic floor muscle action measurable either on instruction to contract (inability) or as the absence of an automatic response to an increase in intraabdominal pressure. This condition can be based on any pelvic floor symptom and on the sign of a non-contracting or non-relaxing pelvic floor.

\footnotetext{
${ }^{9}$ Local or referred pain may be reproduced. An active $\operatorname{Tr} P$ is said to have a characteristic "twitch" response when stimulated, however the twitch response to palpation has been shown to be unreliable [32]. The most reliable sign of a TrP is sensitivity to applied pressure. Trigger points are implicated in myofascial pain, however the validity of this theory is controversial and has recently been refuted [17].
} 
(xiv) Pelvic floor muscle injury (PFMI): on clinical palpation, PFMI is diagnosed when one or more of the following is present: 1 . A discontinuity of the puborectalis muscle at its attachment to the inferior pubic ramus [33]; 2. A distance of $>3.5$ finger widths between the two sides of puborectalis muscle insertion [34,35]; 3. A gap in the continuity of the pubovisceral muscle between the pubic rami and the anorectum [36].

\section{(xv) Muscle action characteristics}

a. Maximal voluntary contraction (MVC): the attempt to recruit as many fibres in a muscle as possible for the purpose of developing force [37]. PFM MVC can be assessed by vaginal palpation, manometers and dynamometers ${ }^{10}$.

b. Muscle strength: force-generating capacity of a muscle [5]. It is generally expressed as maximal voluntary contraction measurements and as the one- repetition maximum (1RM) for dynamic measurements [39,40,37].

c. Local muscle endurance: the ability to sustain near maximal or maximal force, assessed by the time one is able to maintain a maximal static or isometric contraction, or ability to repeatedly develop near maximal or maximal force determined by assessing the maximum number of repetitions one can perform at a given percentage of 1 RM [41].

d. Muscle power: the explosive aspect of strength; the product of strength and speed of movement (force x distance/time) [41].

e. Co-ordination: property of movement characterized by the smooth and harmonious action of groups of muscles working together to produce a desired motion [5].

${ }^{10}$ Palpation is less reliable and responsive than manometers and dynamometers [38]. 
f. Motor control: the ability of the nervous system to control or direct the muscles in purposeful movement and postural adjustment by selective allocation of muscle tension across appropriate joint segments [5,42].

g. Submaximal contraction: all contractions without maximal effort, expressed as a percentage of $1 \mathrm{RM}$.

h. Synergistic contraction: the combination of several muscle actions that serve to optimally achieve a motor task [43].

i. Co-contraction: contraction of two or more muscles at the same time. Co-contraction of muscles can be synergistic (e.g. resulting in an augmentation of motor activity) or it could be counterproductive to normal function (e.g contraction of antagonistic muscles resulting in abnormal movement or training other muscles instead of the targeted ones; e.g. training of gluteal muscles instead of the PFM).

j. Antagonistic contraction: contraction of muscle/muscle groups with opposite action to the wanted action (activity that hinders the targeted muscle/muscle group from contracting).

\section{(xvi) Other}

a. Hypertrophy: the increase in size (volume) of the muscle fibers [43].

b. Atrophy: the decrease in size of muscle fibers as a result of inactivity, illness or aging [44].

c. Bulk: the absolute volume of a muscle measured by imaging techniques such as anatomical magnetic resonance imaging and ultrasonography (US) [45].

d. Anatomic cross sectional area: for an individual muscle, the largest cross-sectional area along the length of that muscle and $90^{\circ}$ on the muscle length [7].

e. Physiological cross-sectional area: the total area of cross-section perpendicular to the muscle fibers [7]. 
f. Flexibility: the ability of a muscle to lengthen and allow one joint (or more than one joint in a series) to move through a range of motion. Loss of flexibility is defined as a decrease in the ability of a muscle to deform [46].

g. Proprioception: sensory information from receptors of muscles, joints, capsules and ligaments that provides information related to posture and movement [47].

h. Exteroception: sensory information from receptors in the skin registering touch, vibration, heat, and cold [47].

\section{SECTION 2: INVESTIGATIONS AND IMAGING}

All methods and devices used for assessments (eg palpation, manometers, dynamometers, EMG, urodynamics, ultrasound and MRI) must be described in detail, and their responsiveness (ability to detect small changes), reliability and validity should be reported [38].

\subsection{Existing (defined) investigations}

\subsection{A. Urodynamics}

Functional study of the lower urinary tract [3].

(i) Uroflowmetry [3]

(ii) Post-void residual (PVR -urine volume) [3]

(iii) Cystometry [3]

(iv) Pressure flow study [3]

(v) Assessment of Urethral Function [3]

a. Urethral pressure measurement [3]

b. Abdominal leak point pressure (ALPP) [3] 


\subsection{B. Frequency-volume chart (FVC)}

The recording of the time of each micturition and the volume voided for at least $24 \mathrm{~h}$, although two or three days of recording (not necessarily consecutive) will generally provide more useful clinical data [3].

(i). Bladder diary: In addition to the FVC, a bladder diary will include fluid intake, pad usage, incontinence episodes and the degree of incontinence [3].

\subsection{Pad testing}

Quantification of the amount of urine lost over the duration of testing, by measuring the increase in weight of the perineal pads (weighed pre-and post-testing) used [3].

\subsection{Ultrasound imaging}

(i) Pelvic floor muscle injury (PFMI): PFMI is diagnosed on ultrasound when at least one of the following is present: 1 . Undetected puborectalis-to-ipsilateral sidewall attachment on any of the three central slices (full avulsion); 2. Undetected puborectalis-to-ipsilateral sidewall attachment on at least one slice (partial avulsion) [48]; 3. A levator-urethra gap (LUG) of greater than $2.5 \mathrm{~cm}[49]$.

(ii) PFM position in the pelvis can be measured in the sagittal plane and can be related to PFM dysfunction (elevated or descended pelvic floor).

(iii) Hiatal dimension is the cross-sectional area of the pelvic floor / levator hiatus, including antero-posterior and transverse distances. 
Figure 1: Levator hiatal dimensions measured using trans-perineal ultrasound (with permission from Ingeborg Hoff Braekken)

\subsection{E. Radiological imaging}

Videocystourethrography (VCU); intravenous urography (IVCU); micturating cystography (MCU); defecography; colpo-cystodefecography.

\subsection{F. Magnetic resonance imaging (MRI)}

(i) Pelvic floor muscle injury can represent a full spectrum from a disruption of a single fascicle, to complete disruption of the muscle origin. At present, there is no universally accepted system for diagnosis and evaluating the extent of the injury. Essentially, abnormalities are judged to have occurred when the morphology of the pubococcygeal portion of the levator ani muscle deviates from what is seen in normal nulliparous women [50]. Several groups studied and have defined levator damage on MRI when one or more of the following is present: Absence of pubococcygeal muscle fibers in at least one 4-mm section or two or more adjacent 2-mm sections in both the axial and coronal planes [51]. The degree of injury can be assessed based on the amount of muscle involved in the injury with reasonable repeatability among different examiners in a single group [52]. More than half the expected muscle bulk is associated with the presence of pelvic organ prolapse [53].

(ii) PFM position in the pelvis: location of the pelvic floor muscles in the sagittal plane in relation to defined landmarks. Can be elevated or descended.

\subsection{Palpation}

The process of using one's fingers / hands as part of assessment, to gather information about the tissues. Digital palpation of the PFM is described by Messelink et al [2]. 
Figure 2: Digital palpation of the pelvic floor muscles (with permission from subjects in photo and photographer Andreas Birger Johansen)

\subsection{Manometer}

A device to measure pressure.

\subsection{A. Pelvic floor manometry}

Measurement of resting pressure or pressure rise generated during contraction of the PFM using a manometer connected to a sensor which is inserted into the urethra, vagina or rectum. Pelvic floor manometric tools measure pressure in either $\mathrm{mmHg}, \mathrm{hPa}$ or $\mathrm{cmH}_{2} \mathrm{O}^{11}$ [38]. Conversion of data to the international standard unit of measurement $(\mathrm{hPa})$ is recommended. Figure 3: Peritron manometer (with permission from Laborie)

Figure 4: Graphical illustration of pelvic floor muscle manometry readings (with permission from illustrator Ingeborg Hoff Braekken)

(i) Perineometer: the first PFM vaginal pressure device connected to a manometer developed by Kegel ${ }^{12}[54]$.

${ }^{11}$ The pressure measured does not confirm its origin, and pressure measurement is only valid when used in combination with other methods e.g. simultaneous observation of inward movement of the perineum or device during PFM contraction.

${ }^{12}$ The perineometer was developed by Kegel [54].The term perineometer is somewhat misleading as the pressure-sensitive region of the manometer probe is not placed at the perineum but inside the vagina at the level of the levator ani. Vaginal pressure devices should be referred to as PFM manometers [38,54]. 


\subsection{Dynamometer}

An instrument which measures power or force [8].

\subsection{A. Pelvic floor dynamometry}

Measurement of PFM resting and contractile forces using strain gauges mounted on a speculum (a dynamometer), which is inserted into the vagina [55]. Dynamometry measures force in Newton units $\left(\mathrm{N}=1 \mathrm{~kg} \mathrm{X} \mathrm{m} / \mathrm{s}^{2}\right)^{13}$.

Figure 5: Ann Arbor, USA, dynamometer speculum. Note that the bills of the speculum are covered by a condom in actual use (with permission from Ashton-Miller JA, Zielinski R, DeLancey JO, Miller JM.)

Figure 6: Montreal, Canada, dynamometer apparatus (with permission from Chantale Dumoulin)

\subsection{Electromyography (EMG)}

The recording of electrical potentials generated by the depolarization of muscle fibers.

\subsection{A. Electromyographic diagnosis}

State of the muscle (muscle pathology) by recording and analysing the electrical activity generated by the muscle ${ }^{14}[42]$.

${ }^{13}$ Todays' dynamometers for the pelvic floor also measures use of muscles other than the pelvic floor muscles. As dynamometers can be opened at different muscle lengths to measure PFM force, the process of measurement should respect the maximum achievable vaginal aperture without inducing discomfort, so as not to influence the validity of the measurement. 
(i) Intra-muscular EMG: insertion of a wire or needle electrode into the muscle to record motor unit action potentials ${ }^{15}$.

(ii) Surface electromyography: electrodes placed on the skin of the perineum or inside the urethra, vaginal or rectum ${ }^{16}$.

Figure 7: Verity Medical NeuroTrac Myoplus Pro surface EMG biofeedback apparatus (also incorporating electrical stimulation (with permission from Quintet, Norway)

${ }^{14}$ EMG in this case usually means "concentric needle EMG", but other EMG methods exist. Electromyography is typically distinguished as intra-muscular or surface. Electromyographic diagnosis is often used as a synonym for "neurophysiological diagnosis of the peripheral neuromuscular system”, and that would also include measurement of motor and sensory conduction, recording of reflex responses etc [42]. EMG measurements are not a direct measure of muscle strength. The type of electrode being used should be specified.

${ }^{15}$ This is not typically used in clinical assessment, but may be included in research or advanced examinations for example to diagnose striated muscle denervation/re-innervation [42].

${ }^{16}$ Surface EMG is considered to be less specific than intra-muscular EMG. The large surface area of the electrodes may result in cross-talk from adjacent muscles, and other artifacts therefore technical expertise is required. EMG can reveal the pattern of activity of a particular muscle as in the diagnosis of detrusor sphincter dyssynergia during urodynamics $[42,2]$. 


\subsection{Pain assessment}

\subsection{A. Pain evaluation}

Baseline and ongoing regular evaluation of severity, quality of life, thoughts, emotions and behavior associated with the pain (via direct consultation or questionnaires) and investigations to identify well-defined/confusable/non-pain syndromes.

\section{(i) Pain measurement}

Pain can only be measured subjectively. Patient-reported outcome measures include:

a. Numerical rating scale (NRS), from 0 (no pain) to 10 (extreme pain), with half-points marked [56,57]

b. Visual analogue scale (VAS), a 10-cm line with the same labels at the ends

c. A simple verbal rating scale can be used, e.g. 'none', 'mild', 'moderate', 'severe'17.

(ii) Pain mapping: identifying pain generators through diagnostic procedures such as questionnaires, digital palpation, EMG, quantitative sensory threshold measurement, trigger point injections, nerve blocks and imaging.

a. Questionnaires: several pain questionnaires can be used in evaluation of musculoskeletal pain in the pelvis; the choice will be determined by which is most appropriate to the presenting pelvic floor dysfunction: McGill Pain Questionnaire [58], Pelvic Floor Distress InventoryPFDI [59], Female Sexual Function Index [60], Female Sexual Distress Scale [61], Pelvic Pain and Urgency/Frequency Questionnaire [62].

\footnotetext{
${ }^{17}$ Because pain is multidimensional, a single rating scale combines these dimensions in unknown quantities. One may separately assess pain intensity, pain distress, and interference of pain with activities of daily life.
} 
b. Pain chart / body map: a simple line drawing of an outline of the front and back (or relevant body part) of the human body, onto which the patient sketches or ticks or marks areas of bodily pain to demonstrate the site and extent of perceived pain [63].

c. Pain checklist: a list of anatomical locations from which the patient selects relevant sites to his/her complaint.

d. Measurement of muscle tone: there is no single tool which is able to measure all components of muscle tone. Some tools may be able to measure aspects of tone such as contractility, stiffness or elasticity. Instrumented methods may have a role in the valid and reliable evaluation of muscle tone e.g. Surface electromyography (sEMG), wire and concentric electromyography, dynamometry, real-time ultrasound, elastometry, myotonometry.

e. Trigger point (TrP) injection or needling: a diagnostic test to confirm if the identified $\operatorname{TrP}$ is a pain generator. The technique is the same as used in $\operatorname{TrP}$ treatment.

f. Imaging: tissue-specific evaluation to identify if morphological trauma or deficit is present, which may relate to the presenting pain. Types of imaging may include X-Ray, ultrasound and MRI.

\section{SECTION 3: DIAGNOSES}

Diagnosis: the act or process of identifying or determining the nature and cause of a disease or injury through evaluation of patient history, examination and review of laboratory data and the opinion derived from such an evaluation [64].

A diagnosis for female PFD is based on the information obtained from the patient's symptoms, signs, and any relevant diagnostic investigations. For the terminology of the 6 most common PFD diagnoses; urodynamic stress urinary incontinence (USI), detrusor 
overactivity (DO), pelvic organ prolapse (POP), voiding dysfunction, bladder oversensitivity and recurrent UTI, the reader is directed to Haylen et al [3].

\subsection{Additional anorectal diagnosis}

(i) Local (fissures, hemorrhoids) [11]

(ii) Fecal incontinence [11]

(iii) Obstructed defecation syndrome [11]

(iv) Rectocele [11]

(v) Enterocele/sigmoidocele [11]

(vi) Intussusception [11]

(vii) Internal mucosal prolapse [11]

(viii) Abscess/fistula[11]

\subsection{Pain syndromes}

(i) Chronic pelvic pain syndrome (CPPS): persistent pain perceived in structures related to the pelvis, in the absence of proven infection or other obvious local pathology that may account for the pain. It is often associated with negative cognitive, behavioural, sexual or emotional consequences, as well as with symptoms suggestive of lower urinary tract, sexual, bowel or gynecological dysfunction [16].

(ii) Chronic pelvic floor muscle pain syndrome: the occurrence of persistent or recurrent, episodic, pain in the PFM, in absence of proven or well-defined local pathology. It is often associated with negative cognitive, behavioural, sexual or emotional consequences, as well as 
with symptoms suggestive of lower urinary tract, sexual, bowel or gynaecological dysfunction $^{18}[16]$.

\subsection{Female sexual dysfunction}

Any departure from normal sensation and/or function expressed by a woman during sexual activity [3].

(i) Dyspareunia [3]

(ii) Obstructed intercourse [3]

(iii) Vaginal laxity [3]

\section{SECTION 4: TREATMENTS}

\subsection{General terms}

${ }^{18}$ Other urological, gynaecological, gastro-intestinal and colo-rectal pain conditions without related PFD, are well described in standard texts. Many pelvic floor pain-related conditions or syndromes (e.g. vulvodynia, interstitial cystitis/bladder pain syndrome, irritable bowel syndrome) are described in the Standard for Terminology in Chronic Pelvic Pain Syndromes (CPPS): A Report from the Ad Hoc Working Group of the International Continence Society Standardization Steering Committee (ICS-SSC) on Chronic Pelvic Pain ICS Standardization of Terminology document on Chronic Pelvic Pain [12]. Several other systemic disorders (e.g. chronic fatigue syndrome, diabetes) may impact on the pelvic floor, however pelvic floor dysfunction is not part of their recognized etiology. 


\subsection{A. Behavioral}

The way someone behaves, especially towards other people, and behavioral science is the study of human behavior [65].

(i) Behavior therapy: a kind of psychotherapy that attempts to modify observable maladjusted patterns of behavior by substituting a new response or set of responses to a given stimulus. The treatment techniques involve the methods, concepts, and procedures derived from experimental psychology; they include assertiveness training, aversion therapy, contingency management, flooding, modelling, operant conditioning and systematic desensitisation. Also called behaviour modification ${ }^{19}$ [14].

(ii) Cognitive therapy: any of the various methods of treating mental and emotional disorders that help a person change attitudes, perceptions and patterns of thinking, from rational to realistic thoughts about self and situations. The technique is often used in association with behavior therapy principles. This approach is called cognitive behavior therapy [14].

(iii) Cognitive behavior therapy (CBT): a collective term for a range of psychotherapeutic techniques that attempt to use a problem-solving approach to the identification of thoughts and behaviors that underpin psychological problems or disorders [14].

\footnotetext{
${ }^{19}$ We recommend that "behavioral" be limited to studies that evaluate how people do or do not behave as desired e.g. commencement or cessation of pelvic floor muscle training or change of a diet.
} 


\subsection{B. Physiotherapy}

Physiotherapy involves "using knowledge and skills unique to physiotherapists" and, "is the service only provided by, or under the direction and supervision of a physiotherapist" ${ }^{20}$ [66].

\subsection{Adherence}

The extent to which a client/patient's behaviour corresponds to the agreed treatment protocol and/or regime as recommended by their healthcare provider [67]. It does not refer to the intervention itself, rather, the patient's commitment to undertaking the behavioural change in order to adhere to the intervention ${ }^{21}$.

\subsection{Compliance}

The extent to which a client/patient's behaviour matches, or complies with, their healthcare provider's recommended treatment protocol and/or regime ${ }^{22}[68]$.

${ }^{20}$ We recommend that the specific treatment is described e.g. pelvic floor muscle training, electrical stimulation rather than the unspecific term physiotherapy; the latter also referring to a specific profession. Publications should report the actual professional who provided the intervention (e.g., physiotherapist, general practitioner, urogynecologist, urologist, midwife, nurse, fitness instructor), rather than using the vague term, "therapist" / "clinician" / "researcher".

${ }^{21}$ Adherence is usually reported as the number or percentage of (1) clinical visits attended and (2) home exercises or regimen components followed or completed by the client/patient.

${ }^{22}$ The term 'adherence' is generally preferred within healthcare as it acknowledges client/patient autonomy and implies a willingness on their part to participate and cooperate rather than the traditional view, inherent in 'compliance', of an expert clinician dictating to a 


\subsection{E. Combination therapy (also known as polytherapy, multimodal therapy or combined}

modality therapy)

Combination therapy is the use of more than one intervention concurrently for a single condition with one or multiple symptoms, for example a combination of medication with PFM training (PFMT).

(i). Adjunctive therapies: any treatment or modality used to augment or assist the main treatment. In conservative treatments, adjunctive therapies often refer to equipment or a secondary therapy used to supplement the effect of the primary therapy, e.g. biofeedbackassisted pelvic floor muscle training or neuromuscular electrical stimulation to augment PFMT,

\subsection{F. Prevention}

The act of preventing; decreasing the risk of disease or disability. Activities that are directed toward slowing or stopping the occurrence of both mental and physical illness and disease, minimizing the effects of a disease or impairment on disability, or reducing the severity or duration of an illness [5].

(i) Primary prevention: prevention of the development of disease in a susceptible or potentially susceptible population through such specific measures as general health promotion efforts [5].

naive patient [67,68].Simply, adherence is agreeing what to do, compliance is being told what to do. 
(ii) Secondary prevention: efforts to decrease the duration of illness, reduce severity of diseases, and limit sequelae through early diagnosis and prompt intervention [5].

(iii) Tertiary prevention: efforts to limit the degree of disability and promote rehabilitation and restoration of function in patients/clients with chronic and irreversible diseases) [5].

\subsection{Lifestyle}

\subsection{A. Lifestyle modification}

The application of interventions in management of lifestyle-related health problems e.g. change to healthy diet and regular participation in physical activity and smoking cessation. The following lifestyle modifications may be applied to treat pelvic floor dysfunctions, either in combination with other therapies or as 'stand-alone' treatments.

(i) Fluid consumption/restriction: fluid consumption is the intake of fluid over 24 hours. Fluid restriction is the limitation of fluid to a prescribed amount over a period of 24 hours. These measures are often undertaken as part of a bladder training process.

(ii) Dietary modification: an alteration or adjustment of food to treat bowel disorders (e.g. constipation and faecal incontinence) or urinary disorders (e.g. incontinence or urgency), e.g. increase of fibre to treat constipation. Specifics of the dietary changes should be described.

(iii) Elimination diet: a form of dietary modification. A diet designed to detect what ingredient in the food causes symptoms in the patient, foods items of which the patient may be sensitive are withdrawn separately and successfully from the diet until the item that causes 
the symptoms is discovered. Used frequently in patients with faecal incontinence, urgency and urgency incontinence (bladder diet) [69,70].

(iv) Physical activity: any body movement produced by the skeletal muscles that result in a substantial increase over the resting energy expenditure. Physical activity can be done at work, as transportation, as household and other chores and leisure-time/ sport and fitness activities $^{23}[72]$.

\subsection{B. Counseling}

The provision of professional assistance and guidance in resolving personal or psychological problems [7]. Counselling may be is part of any clinician's management.

(i) Patient education: providing patients with knowledge and understanding of their condition thereby empowering them to play an active role in its management [73].

Figure 8: Patient education of pelvic floor muscle function (with permission from Women's and Men's Health Physiotherapy)

(ii) Motivational interviewing: a directive, client-centered counselling style for eliciting behaviour change by helping clients to explore and resolve ambivalence. Compared with

${ }^{23}$ Increase of physical activity level may affect UI positively via weight reduction in obese persons. Conversely, several studies have shown that there is a high prevalence of UI in physically active women during exercise (especially during high impact activity, defined as running and jumping). Strenuous exercise/work has been suggested as a risk factor for development of pelvic floor dysfunctions [71]. A well-functioning pelvic floor will respond before and during an increase in intra-abdominal pressure. 
nondirective counselling, it is more focused and goal-directed. The examination and resolution of ambivalence is its central purpose, and the counsellor/clinician is intentionally directive in pursuing this goal [74].

(iii) Coping strategies: intervention aimed at helping patients to live with the condition as best as possible under the circumstances, to regain a feeling of being in control, to adjust their lifestyle where necessary and to take a positive rather than negative approach [73].

(iv) Self-care: the set of activities that comprise daily living, such as bed mobility, transfers, ambulation, dressing, grooming, bathing, eating, and toileting [5].

(v) Self-help: various methods by which individuals attempt to remedy their difficulties without making use of formal care providers [5].

(vi) Self-efficacy: an individual's belief that he or she is capable of successfully performing a certain set of behaviors [75].

\subsection{Scheduled voiding regimes}

Toileting on a fixed schedule around the patient's normal voiding pattern which includes a progressive voiding schedule using relaxation and distraction techniques for urgency suppression [76]. Scheduled voiding regimes have been categorised as: bladder training, timed voiding, habit training and prompted voiding [71]. 


\subsection{A. Bladder training}

(Also referred to in the past as bladder drill, bladder discipline, bladder re-education, bladder re-training).

A program of patient education along with a scheduled voiding regimen with gradually adjusted voiding intervals. Specific goals are to correct faulty habit patterns of frequent urination, improve control over bladder urgency, prolong voiding intervals, increase bladder capacity, reduce incontinent episodes and restore patient confidence in controlling bladder function $^{24}$ (modified from Moore et al) [71].

\subsection{B. Timed voiding}

A passive toileting assistance program, initiated and maintained by caregivers for patients who cannot participate in independent toileting. It is a fixed voiding schedule [71].

\subsection{Habit training}

A toileting schedule matched to the individual's voiding patterns based on their voiding diary. The toileting schedule is assigned to fit a time interval that is shorter than the person's normal voiding pattern and precedes the time period when incontinent episodes are expected [71].

\subsection{Prompted voiding}

Is used to teach people to initiate their own toileting through requests for help and positive reinforcement from caregivers, often done in combination with a scheduled voiding regimens, typically every two hours [71].

${ }^{24}$ Ideally the voiding intervals should be increased by 15-30 minutes each week, according to the patient's tolerance to the schedule, until a voiding interval of 3-4 hours is achieved. Use of a bladder diary is recommended for self-monitoring of progress [76]. 


\subsection{Other techniques for bladder and bowel control}

Doing something that takes the mind off the condition. Distraction techniques utilized in urgency may include (but are not limited to) count backwards from 100 in 7 seconds, recite a poem, do breathing exercises, read or work.

\subsection{B. Urgency suppression techniques}

Methods/manoeuvres used to decrease the feeling of urgency which may include, but are not limited to: distraction, PFM contraction, perineal pressure such as sitting on a hard chair, relaxation and breathing, toe curling or plantar flexion of the ankle.

\subsection{Double voiding}

The patient is taught to urinate, relax and attempt to urinate again [64].

\subsection{Defecatory dynamics}

A postural and respiratory technique to aid defaecation. The mechanics involves coordination of the diaphragm, abdominal and pelvic floor muscles, with intent to maintain the rectal support whilst releasing the anal outlet with sufficient expulsion to be effective $[77,78]$. 


\subsection{E. Bowel habit training}

The training aim to establish a regular, predictable pattern of bowel evacuation by patient teaching and adherence to a routine to achieve a controlled response to bowel urgency ${ }^{25}$ (modified from NICE guideline) [80].

\subsection{Exercise/exercise training}

Exercise is a form of leisure-time activity that is usually performed on a repeated basis over an extended period of time (exercise training) with specific external objectives such as improvement of fitness, physical performance, or health [72]. Exercise training includes: endurance training, strength training, flexibility training and motor control (including balance), all of which may apply to the pelvic floor muscles.

\subsection{A Therapeutic exercise / exercise therapy}

Exercise interventions directed toward maximizing functional capabilities. A broad range of activities intended to improve strength, range of motion (including muscle length), cardiovascular fitness, flexibility, or to otherwise increase a person's functional capacity [5].

\section{(i) Rehabilitation / re-education}

\footnotetext{
${ }^{25}$ A bowel habit intervention may: encourage bowel emptying at a specific time of day, mainly after a meal (to utilise the gastrocolic response), encourage people to adopt a sitting or squatting position where possible while emptying the bowel, teach people techniques to facilitate bowel evacuation and stress the importance of avoiding straining [79-81].
} 
Helping individuals regain skills and abilities that have been lost as a result of illness, injury or disease, disorder, or incarceration. The restoration of a disabled individual to maximum independence commensurate with his or her limitations [5].

\subsection{B. Mode of exercise training}

Not only the type of activity to be performed (for instance, fast walking, jogging, or swimming, strength training), but also the temporal pattern of activity that is recommended (that is, continuous or intermittent activity), with a detailed specification of the duration of exercise and rest periods in the case of intermittent activity bouts [72]. Authors are encouraged to specifically describe all components of mode of exercise and dose provided.

(i) Muscle training: exercise to increase muscle strength, endurance, power, flexibility or relaxation.

a. Strength training: training with high resistance (close to maximal contractions) and few repetitions with the aim to increase muscle volume and neural adaptations.

b. Resistance: the amount of force opposing a movement [45].

c. Resistance devices: any object used to increase resistance to contraction e.g. hand weights. d. Vaginal resistance device: objects inserted into the vagina or rectum that are inflated or spring loaded devices to increase resistance to contraction.

e. Local muscle endurance training: training with low load and high number of repetitions or holding the contraction over time. 
f. Muscle power training: all training with the aim to generate power; can be close to maximal contraction training and/or rapid contractions ${ }^{26}$.

g. Overload: a situation in which the body is required to perform exercise beyond that which the neuromuscular system is accustomed to during routine activities. A training adaptation occurs in response to a progressive "overload" [82].

h. Progressive overload: the gradual increase of stress placed upon the body during exercise training [83].

i. Detraining: cessation of training, but also planned or unplanned reduced volume or intensity of training [84].

j. Maintenance training: maintenance training refers to a program designed to prevent loss of previous level of functioning.

k. Isometric/static contraction: a muscular action during which no change in the length of the total muscle or joint angle takes place [84].

I. Isotonic contraction: a muscular action during which the tension developed by the muscle remains almost constant while the muscle shortens [85].

m. Eccentric contraction: a muscular action in which the muscle lengthens in a controlled manner ${ }^{27}[84]$.

n. Repetition: the completion of a whole cycle from the starting position, through the end of the movement and back to the start. [82]. E.g. one PFM contraction with relaxation.

o. Set: the number of times the desired number of repetitions is performed [39]. E.g. 3 sets of 12 PFM contractions.

${ }^{26}$ Speed changes little with training. Thus, power is increased almost exclusively through gains in strength [41].

${ }^{27}$ PFM training can be isometric, concentric or eccentric or combination of any of these. 
p. Pelvic floor muscle training (PFMT): exercise to improve PFM strength, endurance, power, relaxation or a combination of these parameters.

q. Kegels: a PFM contraction or PFM exercise. This term is named after Arnold Kegel, an American gynaecologist who first described the clinical effect of PFMT in the late 1940s [54]. We recommend the use of the term PFMT (not the word Kegels') to refer to exercises which specifically target the PFM.

r. Individualized pelvic floor muscle training: an individual PFM program aimed to improve the specific deficiencies in PFM structure or function based on assessment of the woman's ability to contract the PFM.

s. Supervised pelvic floor muscle training: a PFM training program taught and monitored by a health professional/clinician / instructor.

t. Group pelvic floor muscle training: PFM training conducted in an exercise class [86].

Class participation may occur with or without prior individualized PFM instruction ${ }^{28}$.

u. Home training/home PFM exercise program: an unsupervised PFM training program, which the individual performs at home.

v. Weighted vaginal cones: objects of different shapes, sizes and weight which are inserted into the vagina above the level of the PFM with the aim of providing sensory biofeedback and load on the PFM to increase muscle recruitment and strength ${ }^{29}$ [87].

${ }^{28}$ Whether PFMT is performed with or without prior assessment of ability to contract should be reported.

${ }^{29}$ The original shape was conical, however different shapes are currently available. Maintenance of the weight in position can be challenged via different body positions and activities. 
(iii) Facilitation technique: any method to increase recruitment/response of a nonresponding muscle. In the case of non-contractile or very weak PFMs, this may include a quick stretch to the PFM with tapping or stretching the PFM digitally. An overflow effect from a strong contraction of a nearby synergistic muscle (e.g. external rotators) may also assist facilitation or recruitment of PFMs.

\subsection{Dose-response issues related to exercise training}

(i) Dose-response: amount/volume of training and its effect on, the speed of, and degree of effect of the training program.

(ii) Frequency of exercise: the number of activity sessions per day, week, or month [39].

(iii) Duration of exercise: the unit of time (number of seconds / minutes) of activity in each repetition or session, e.g. a $10 \mathrm{sec}$ PFM contraction [39]. It also refers to the length of the whole training period (intervention); e.g. 3 / 6 months.

(iv) Intensity: the amount of resistance used or effort associated with the physical activity [39]. For strength training, it is often expressed as \% of "one repetition maximum: 1RM (the maximum load a person can lift once), e.g $70 \%$ of $\max [82]$.

(v) Session / bout: the block of time devoted to the training e.g a one hour session [82].

\subsection{Relaxation training}

(i) Relaxation: the ability to control muscle activity such that muscles not specifically required for a task are quiet, and those which are required are fired at the minimal level 
needed to achieve the desired results [88]. Relaxation "can be considered as a motor skill in itself because the ability to reduce muscle firing is as important to control as is generation of firing" [46].

a. General relaxation technique: a technique which involves the whole body, with the aim to effect a global relaxation including decrease in skeletal and smooth muscles, decrease in heart rate, respiration rate and increase in parasympathetic activity. General relaxation techniques can also be used with the aim to relax local muscles.

b. Progressive muscular relaxation (also known as Jacobsen's technique): monitoring tension in each specific muscle group, by contracting, then relaxing the tension, with attention paid to the contrast between tension and relaxation [89]. This type of relaxation is also termed "contract-relax".

c. Meditation: a practice of concentrated focus upon a sound, object, visualization, the breath, movement, or attention itself in order to increase awareness of the present moment, reduce stress, promote relaxation, and enhance personal and spiritual growth [90].

d. Mindfulness: intentionally bringing one's attention to the internal and external experiences occurring in the present moment. Mindfulness is often taught through a variety of meditation exercises [91].

e. EMG relaxation techniques: techniques to decrease EMG muscle activity or activation through a variety of methods including conscious effort to relax.

\subsection{E. Stretching}

(i) Stretching (also referred to as flexibility training when the method is used on skeletal muscles where increased range of motion over joints is the aim): the application of an external force to muscle and connective tissue to elongate it in the direction opposite to its 
shortened position. This can be done in parallel with or perpendicular to muscle fibre direction. For the PFM this can be applied as a widening of the levator hiatus in the axial plane (latero-laterally) via a digit or use of dilator, or a caudal movement (via a straining/bearing down manoeuvre) in the sagittal plane.

a. Dilator therapy: a conical or cylindrically-shaped device (made of an inert material) inserted intra-vaginally or intra-anally, with the aim to increase the flexibility or elasticity of the soft tissues via application of a prolonged elongation or stretch. Dilators may also be used as a de-sensitizer device, in order to reduce fear, anxiety or pain associated with vaginal touch and in conjunction with vaginismus or sexual pain. When combined with EMG, dilators can be used to train PFM relaxation during penetration. Dilators may also be used to increase tolerance of skin to sliding when the dilator is moved in and out.

\subsection{F. Functional training}

Training in tasks of daily living and self-care activities e.g. squatting to train quadriceps and gluteal muscles.

(i) Functional PFM training: training and exercises which incorporate a correct PFM contraction into activities of daily living such as lifting, transferring out of bed, or sneezing. A PFM contraction prior to a rise in intra-abdominal pressure e.g. a cough ("the Knack") is part of functional PFM training.

(ii) Coordination training: the ability to use different parts of the body together smoothly and efficiently [7]. Related to PFM training, coordination training means PFM contraction with other muscles or other muscle groups e.g. respiratory muscles. 
(iii) Functional mobility training: an intervention directed at improving physical ability to perform a daily task. For voiding / defecation, this may include: gait training, transfer training, stair training, and other mobility training to improve speed and safety in reaching the toilet.

\subsection{Biofeedback training}

\subsection{A. Feedback}

Sensory information that is available as the result of an activity that a person has performed. It can be provided by an intrinsic source (from within the individual), or an extrinsic source (from the clinician), and can occur concurrently with the activity or post-activity. E.g. verbal information from the clinician to the patient during or following PFM assessment ${ }^{30}$ [92].

\subsection{B. Biofeedback}

Use of an external sensor to give an indication on bodily processes, usually in the purpose of changing the measured quality [93]. It is an adjunctive therapy ${ }^{31}{ }^{32}$.

${ }^{30}$ PFM feedback can be provided by the therapist or patient during manual palpation internally or externally, or with a mirror. The purpose of feedback is to increase accuracy of contraction for maximum benefit.

${ }^{31}$ Biofeedback can be either visual, auditory or both. Biofeedback is not a treatment on its own. It is an adjunct to training and can be used to help the patient be more aware of muscle function, and to enhance and motivate patient effort during training [94]. The correct terminology should be PFM strength training with biofeedback or relaxation training with biofeedback. 


\subsection{EMG Biofeedback Unit Instrumentation}

(i) EMG signal amplitude: amount of microvolts (uV) a muscle is generating [95]. EMG biofeedback units can deliver either the actual amount of EMG activity in uV or an average $(\mathrm{uV})^{33} 34$

(ii) Artifact: extraneous information non- recognizable in EMG signal from sources other than the target muscle such as the environment or other body functions ${ }^{35}$ [95].

(iii) Cross talk: muscle activity from nearby muscles which can artificially increase EMG amplitude. A type of $\operatorname{artifact}^{36}$ [95].

(iv) Dual channel EMG: use of two channels to monitor two separate muscle or muscle groups at the same time such as the PFM and abdominal muscles with the goal to either

\footnotetext{
${ }^{32}$ Types of pelvic floor muscle biofeedback include: perianal, vaginal and anal surface EMG, urethral, vaginal or anal manometry, vaginal dynamometry, real-time ultrasound [94].

${ }^{33}$ Clinicians are to be cautious in regard to the interpretation of the information as many factors influence amplitude including muscle activity, skin conductance, and artifact. 34 "EMG amplitude does not equal force" [95]. More microvolt activity means more muscle activity but does not always mean more strength.

${ }^{35}$ Artifact examples: movement or contact quality artifact, cross talk, heart rate, skin electrode shear, electrode bridging, and others.

${ }^{36}$ Minimizing cross talk is essential in research for quality EMG tracings.
} 
promoting synergist activity or to reduce EMG activity of one muscle while increasing the other.

(v) Band pass: limits muscle fiber frequencies that are monitored and displayed in the EMG $\operatorname{tracing}^{37}[95]$.

\subsection{PFM EMG Assessment}

Use and interpretation of surface EMG recording of a muscle for rehabilitation purposes should be done cautiously recognizing the main goal is qualitative description of muscle activation pattern not qualitative diagnosis.

(i) Baseline muscle activity: amount of microvolts generated by the target muscle during rest $^{38}$

(ii) Peak microvolts: highest EMG amplitude achieved.

(iii) Slow recruitment: slow initiation of muscle activation contraction ${ }^{39}$.

${ }^{37}$ Recording with surface electrodes is prone to artifact and cross talk. The user should be trained appropriately and understand the limit of the EMG instrument and of the methodology. It is not within the scope of this document to define all EMG terms. Readers are referred to other texts for further terminology [95,96].

${ }^{38}$ Baseline EMG reading can be influenced by many factors and therapists must take into account patient's symptoms, digital palpation results, overall tension of the patient, possibility of artifact, and other factors in determining the meaning of the baseline muscle activity. 
(iv) Slow de-recruitment or slow latency to return to baseline: slow relaxation of the muscle contraction $^{40}[96]$.

(v) Inconsistent resting baseline: variation of baseline between contractions, between sets, or between days may be related to a change in patient symptoms e.g hypertonic PFM.

(vi) Excessive accessory muscle contraction: increased amplitude in accessory muscles often resulting in cross talk and indicative of poor isolation of target muscle contraction.

\subsection{E. PFM EMG training}

(i) Up-training: EMG biofeedback training to increase the EMG activity of a hypotonic muscle with low EMG activity ${ }^{41}[95]$.

(ii) Down-training: EMG biofeedback training to decrease EMG activity and relax muscle ${ }^{42}$ [95].

${ }^{39}$ Slow recruitment can be symptomatic of leakage during coughing and sneezing when a quick muscle contraction is needed to counteract increased intra-abdominal pressure.

${ }^{40}$ Slow de-recruitment can be indicative of an hypertonic PFM.

${ }^{41}$ The general principles of strength training are the same with and without biofeedback. (See mode of exercise training and dose response issues)

${ }^{42}$ The general principles of relaxation training are the same with and without biofeedback. 


\subsection{Manual therapy}

A clinical approach utilizing skilled, specific hands-on techniques, including but not limited to massage, manipulation or mobilization ${ }^{43}$.

\subsection{A. Joint therapies}

(i) Mobilization: skilled passive movement of a skeletal joint which includes graded passive oscillations at the joint to improve joint mobility e.g. movement of the coccyx.

(ii) Manipulation: a passive (for the patient) therapeutic movement, usually of small amplitude and high velocity, at the end of the available joint range [5]. Manipulation is a sudden small thrust that is controlled by the clinician ${ }^{44}$.

\subsection{B. Soft tissue therapies}

(i) Touch de-sensitization: use of finger / hand, vibration or device to reduce hypersensitivity of soft tissues to touch / contact.

(ii) Massage: the manipulation of the soft tissues of the body for the purpose of affecting the nervous, muscular, respiratory, and circulatory systems [5].

\footnotetext{
${ }^{43}$ Manual therapy is used to treat soft tissues and joint structures for the purpose of modulating pain; increasing range of motion; reducing soft tissue oedema; inducing relaxation; improving contractile and non-contractile tissue extensibility, and/or stability; facilitating movement, and improving function. This broad group of skilled hands-on treatments can be divided into two groups: joint therapies and soft tissue therapies. ${ }^{44}$ Neither mobilization nor manipulation should be used when referring to muscle.
} 
(iii) Abdominal massage: therapist or self-directed massage of the abdominal wall with the aim to stimulate peristalsis and relieve the symptoms of constipation. Generally the technique follows the ascending, transverse and descending colon to aid emptying. The effect may be mechanical or sensory [97].

(iv) Myofascial release techniques: the use of deep friction and stroking of the fascia of the body to improve the ability of the fascia to deform and move within the body [5].

(v) Skin rolling: a manual technique in which skin is pulled away from the underlying structures and elongated in various directions.

(vi) Scar massage: a specific application of soft tissue mobilization to adherent scar.

(vii) Perineal massage: intra-vaginal massage by the woman, her partner or the clinician. Technique includes alternating downward and sideward pressure, using thumb and forefinger and a natural oil, with the aim to stretch and elongate the tissue in preparation for vaginal childbirth, or for treatment of adherent scaring in the perineum [98].

(viii) Transverse friction: the operator's fingertip is placed on the exact site of the lesion and rubbed firmly across the direction of the fibers of the affected tissue [99].

(ix) Thiele's massage: per rectal digital massage of levator ani, sweeping lengthwise along the muscle fibres. Massage is begun lightly, and pressure is increased as tenderness decreases [100]. 
(x) Trigger point treatment $(\operatorname{TrP})$ : (sometimes called myofascial trigger point treatment): soft tissue mobilization specifically targeting trigger points and may include ischemic pressure, massage, myofascial release, electrotherapy, ultrasound, laser, spray-and-stretch, injection (variety of chemicals including local anesthetic, botox or steroids), dry needling (insertion of solid needle into the $\operatorname{TrP}$ ), and stretching ${ }^{45}$.

\subsection{Thermal modalities}

\subsection{A. Cold treatment / cryotherapy}

The application of ice for therapeutic purposes. It is used in the initial management of acute musculoskeletal injuries, in order to decrease oedema through vasoconstriction and reduce secondary hypoxic injury by lowering the metabolic demand of injured tissues [30].

\subsection{B. Heat treatment (moist or dry)}

The application of heat to a body part, with the aim to relieve pain and/or stiffness. Usually applied when an injury is older than 48 hours.

\subsection{Electrical therapy}

Use of electric potential or currents to elicit therapeutic responses. Current may be directed at motor or sensory functions. It is not within the scope of this document to define all electrical stimulation terms. Readers are referred to more complete text-books [101].

${ }^{45}$ Trigger points as the cause of myofascial pain is controversial [17]. 


\subsection{A. Electrical muscle stimulation (EMS) (also known as neuromuscular electrical}

\section{stimulation (NMES) or electromyo stimulation)}

The application of electric impulses directly to striated pelvic floor muscle (end-plate) to facilitate contraction. EMS is often referred to as pelvic floor muscle electrical stimulation (PFES) or functional electrical stimulation. PFES is the application of electrical current to the pelvic floor muscle [102]. All of these stimulations may (indirectly) cause inhibition of the detrusor contraction.

Figure 9: Myomed pelvic floor machine, including electrical stimulation (with permission from Enraf-Nonius)

\subsection{B. Mode of application}

(i) Surface electrodes: non-invasive placement of electrodes including intra-vaginal and intra-anal electrodes; in contrast to electrodes which pierce the skin, i.e. needle stimulation.

\section{a. Non-invasive electrical nerve stimulation $[103,104]$ or transcutaneous electrical nerve} stimulation (TENS): the application of electrical energy to stimulate cutaneous nerve and peripheral motor nerves, via suprapubic, perineal or sacral placement of electrodes, or other external sites, or intra-vaginal or intra-anal plug electrodes.

There are two main types of electrical stimulation with surface electrodes:

- Long-term or chronic electrical stimulation is delivered below the sensory threshold. It aims to inhibit detrusor activity by afferent pudendal nerve stimulation. The device is used 6 to 12 hours a day for several months [105]. 
- Maximal neuromuscular electrical stimulation applies a high-intensity stimulus, set just below the pain threshold. It aims to improve urethral closure, via striated muscle recruitment. Detrusor inhibition by afferent pudendal nerve stimulation has also been suggested as a mechanism of effect [103]. Maximal electrical stimulation $(35-70 \mathrm{~Hz})$ is applied over short duration (15 to 30 minutes), is used several times per week (and up to 1 to 2 times daily), and may be provided via in-clinic application or via portable devices at home) [106-108].

(ii) Percutaneous electrical nerve stimulation (PENS): a therapeutic modality that stimulates peripheral sensory nerves performed with a (few) needle electrode(s) that are placed in close proximity to the area to stimulate. - Percutaneous neuromuscular electrical stimulation (e.g. posterior tibial nerve stimulation): a peripheral neuromodulation technique, in which the posterior tibial nerve is electrically stimulated three fingerbreadths above the medial malleolus, via insertion of a percutaneous needle electrode. This is coupled with an adhesive reference surface electrode placed near to the needle. This intervention is offered to patients with overactive bladder (OAB) [109-111].

\subsection{Electrophysiological parameters}

(i) Electrical Current: the flow (current) of electrons (electricity) from an electron source (stimulator) the wires and electrodes used to deliver such an electrical current to soft tissues [112].

There are 3 types of current: direct, alternating and pulsed. -

a. Direct: the continuous, unidirectional flow of charged particles for 1 second or longer, the direction of which is determined by the polarity selected. Polarity refers to two oppositely 
charged poles, one positive and one negative. Polarity determines the direction in which current flows [112].

b. Alternating: the continuous, bidirectional flow of charged particles, for one second or longer, relative to the isoelectric baseline [112].

c. Pulsed: the non-continuous, interrupted and periodic flow of direct (DC) or alternating (AC) currents [112].

Currents used in therapy:

a. Faradic current: an alternating and interrupted low frequency current capable of stimulating (depolarizing) nerve fibers through the skin using surface stimulating electrodes. It is used to stimulate innervated muscles causing them to contract [113].

b. Transcutaneous electrical nerve stimulation (TENS): an alternating and interrupted low frequency current capable of stimulating (depolarizing) nerve fibers through the skin using surface stimulating electrodes for pain modulation or pain relief [112].

c. Interferential current: (IFC), a medium frequency, amplitude modulated electrical current that results from the interference (hence the word interferential) caused by crossing two or more medium frequency alternating sine-wave currents with different carrier frequencies. The carrier frequency of theses medium alternating sine wave currents ranges between 2000 and 5000 cycles per seconds [112]. 


\subsection{Neuromuscular Electrical stimulation parameters ${ }^{46}$}

(i) Pulse frequency (or rate): the number of pulse cycles that are generated per unit of time (seconds). This is reported as hertz (Hz) [112].

(ii) Pulse width: the determined period of time elapsing from the beginning to the end of one pulse cycle, usually express in microseconds or milliseconds [112].

(iii) Current amplitude: the magnitude of current relative to the isoelectric baseline, expressed in amperes (A). The current amplitude of therapeutic electrical stimulators ranges in micro to milliamperes [112].

(iv) Train: the continuous series of pulse cycles over time, usually lasting seconds. For example, a train of impulses may be the results of successive pulse cycles delivered at $50 \mathrm{~Hz}$ for a duration of 5 seconds [112].

(v) Train ramp-up time and ramp-down time: ramp-up time is the time elapse from the onset (or baseline) to plateau current amplitude (or maximum) of the train, whereas rampdown time is the time elapsed from the plateau current amplitude to zero baseline ${ }^{47}$ [112].

${ }^{46}$ Depending on the particular device being used, type of electrical current, the specific health problem and condition being treated, the individual's needs and circumstances, many electrical stimulation parameters may be adjusted by the therapist administering the treatment.

${ }^{47}$ The slower the current intensity rise to the pre-set amplitude or threshold level, the more comfortable the stimulation may feel. Conversely, the faster the ramp, or the more vertical the ramping up signal, the more discomfort may be felt. 
(vi) Duty cycle (D): it is the ratio of ON-time to the summation of ON-time + OFF time, expressed as a percentage $($ duty cycle $=(\mathrm{ON}) /(\mathrm{ON}+\mathrm{OFF}$ time $) \times 100$. E.g.: a duty cycle of $20 \%$ is calculated when the ON- and OFF times equal 10 and 40 seconds, respectively [112].

(vii) Impedance (electric resistance): the opposition of our biological tissues to the flow of an electrical current. Measured in ohms and designated by Z. [112].

(viii) Evoked potentials: electrical potentials recorded from the nervous system following a delivered stimulus. Not pertinent for electrical stimulation as an intervention.

\subsection{Magnetic stimulation}

(or Extracorporeal Magnetic Innervation (ExMI): a pulsed magnetic technology developed for the transmission of nerve impulses which aims to cause pelvic floor muscle contraction. Persons receive therapy by sitting in a chair, which contains the device that produces the pulsing magnetic fields.

\subsection{Mechanical devices}

\subsection{A. Intravaginal devices}

Devices intended to provide some support to the bladder neck and possibly some compression to the urethra, to correct urinary stress incontinence. These can be traditional tampons, pessaries and contraceptive diaphragms and devices designed specifically to support the bladder neck (removable reusable intra-vaginal ring or single-use disposable devices [114]. 


\subsection{B. Anal plugs}

Types of containment devices that aim to block the loss of stool to control faecal incontinence. Plugs come in different designs, sizes and composition such as polyurethane and polyvinyl-alcohol ${ }^{48}[115]$.

\subsection{Rectal irrigation}

The use of liquid solutions given by enema to remove material from the rectum [116].

\subsection{Urethral plugs}

Intra-urethral devices are types of containment products that aim to block urine leakage [117].

\subsection{E. Pessaries}

Intravaginal devices used to try to restore the prolapsed organs to their normal position and hence to relieve symptoms. Vaginal pessaries can be broadly divided into two types: support pessaries (Ring, Ring with support, Gehrung, Hodge, Shelf) and space filling pessaries (Doughnut, Gellhorn, Cube, Inflatable pessaries) [117-119].

\subsection{Hygiene}

\subsection{A. Bladder hygiene}

Prevention of urinary tract infection by using techniques such as wiping the urethral meatus with clean wipes in an anterior-to-posterior direction after voiding, wearing clean underwear, keep the genital area clean, and emptying the bladder before and after sexual intercourse $[120,121]$

\footnotetext{
${ }^{48}$ Terminology for female Anorectal Dysfunction [11].
} 


\subsection{B. Vulval hygiene}

Maintaining a clean perineum by means of washing the area on a regular basis, and wearing cotton underwear. To avoid vulval irritation, shampoo, perfumed creams or soap should be avoided in the vulval area [122].

\subsection{Anal hygiene}

Anal hygiene involves keeping the peri-anal region clean, especially important when fecal seepage is present. Advice includes using soft toilet paper or moist wipes (avoiding any with an alcohol base), always wiping from to back, washing after a bowel movement, then gently patting dry [97]. To avoid irritation from products, follow vulval hygiene advice above.

\subsection{Vaginal lubricants}

Pharmacologic preparations aimed to reduce friction during coital or any other sexual activity and thereby alleviate dyspareunia [123], or to reduce discomfort associated with a clinical (per vaginum or per rectum) examination. Pharmacological preparations and natural plantbased oils may be used.

\subsection{Aids and appliances}

\subsection{A. Absorbent products}

Products which have been specifically developed to help manage leakage or soiling such as absorbent pads and pants, absorbent bed sheets and chair covers [114,124]. 


\subsection{B. Catheters}

Urinary catheters are small tubes inserted via the urethra or into the bladder suprapubically, to allow drainage of urine. Catheters are made of plastic, latex, teflon or silicone, and may be impregnated with antiseptic or antibiotic solution [125].

(i) Self-catheterization: a procedure performed intermittently to empty the bladder by inserting a catheter into the urethra when normal voiding is not possible or the bladder cannot be emptied completely. If a care-giver undertakes this procedure it is usually a sterile procedure; if a patient undertakes it, it is termed "self-catheterization" and is generally a clean rather than a sterile procedure [126-128].

Acknowledgement: We thank Professors Jacques Corcos (Urologist McGill University, Montreal Canada, Mandy Fader (Nurse, University of Southampton, UK), Ingrid Nygaard (Urogynecologist, University of Utah, Salt Lake City, USA), Marijke van Kampen (Physiotherapist, University Hospital Gasthuisberg, K.U. Leuven, Belgium) and David Vodusek (Neurophysiologist, University of Ljubljana, Slovenia) for expert advice on the draft manuscript. 


\section{REFERENCE LIST}

1. Abrams P, Cardozo L, Fall M, Griffiths D, Rosier P, Ulmsten U, van Kerrebroeck P, Victor A, Wein A (2002) The standardisation of terminology of lower urinary tract function: report from the Standardisation Sub-committee of the International Continence Society. Am J Obstet Gynecol 187 (1):116-126

2. Messelink B, Benson T, Berghmans B, Bo K, Corcos J, Fowler C, Laycock J, Lim PH, van Lunsen R, a Nijeholt GL, Pemberton J, Wang A, Watier A, Van Kerrebroeck P (2005) Standardization of terminology of pelvic floor muscle function and dysfunction: report from the pelvic floor clinical assessment group of the International Continence Society. Neurourol Urodyn 24 (4):374-380. doi:10.1002/nau.20144

3. Haylen BT, de Ridder D, Freeman RM, Swift SE, Berghmans B, Lee J, Monga A, Petri E, Rizk DE, Sand PK, Schaer GN (2010) An International Urogynecological Association (IUGA)/International Continence Society (ICS) joint report on the terminology for female pelvic floor dysfunction. Neurourol Urodyn 29 (1):4-20. doi:10.1002/nau.20798

4. Bump RC, Norton PA (1998) Epidemiology and natural history of pelvic floor dysfunction. Obstet Gynecol Clin North Am 25 (4):723-746

5. Bottomley JM (2013) Quick reference dictionary for physical therapy. 3rd ed. edn. Slack, Thorofare, N.J

6. Abrams P, Cardozo L, Wein A (2014) Fourth international consultation on incontinenceresearch society 2013. Neurourol Urodyn 33 (5):571-572. doi:10.1002/nau.22617

7. Oxford dictionary. http://oxforddictionaries.com/ Accessed 20 October 2015

8. Merriam-webster online dictionary http://www.merriam-webster.com/dictionary/ Accessed 20 October 2015

9. Bo K, Herbert RD (2013) There is not yet strong evidence that exercise regimens other than pelvic floor muscle training can reduce stress urinary incontinence in women: a systematic review. J Physiother 59 (3):159-168. doi:10.1016/s1836-9553(13)70180-2

10. Bo K, Herbert RD (2009) When and how should new therapies become routine clinical practice? Physiotherapy 95 (1):51-57. doi:10.1016/j.physio.2008.12.001

11. Sultan A, Monga A, Lee J, Emmanuel A, Norton C, Santoro G, Hull T, Berghmans B, Brody S, Haylen BT (2016) An International Urogynecological Association (IUGA) / International Continence Society (ICS) Joint Report on the Terminology for Anorectal Dysfunction in Women (In Committee Review). In manuscript

12. Doggweiler R, Whitmore KE, Meijlink JM, Drake MJ, Frawley H, Nordling J, Hanno P, Fraser MO, Homma Y, Garrido G, Gomes MJ, Elneil S, van de Merwe JP, Lin ATL, Tomoe H (2016) A Standard for Terminology in Chronic Pelvic Pain Syndromes (CPPS): A Report from the Working Group of the International Continence Society Standardisation Steering Committee (ICS-SSC) on Chronic Pelvic Pain. In manuscript

13. IASP Taxonomy. (2012) International Association for the Study of Pain (IASP). http://www.iasp-pain.org/Taxonomy - Pain. Accessed 5 November 2015

14. Harris P, Nagy S, Vardaxis N (2010) Mosby's dictionary of medicine, nursing and health professions. 2nd edn. NSW Elsevier Australia, Chatswood

15. Baranowski A, Abrams P, Berger R, Buffington T, Collett B, Emmanuel A, Fall M, Hanno P, Howard F, Hughes J, Nickel C, Nordling J, Tripp D, Vincent K, Wesselmann U, C de C Williams A (2012) Classification of Chronic Pain: Descriptions of Chronic Pain Syndromes and Definitions of Pain Terms. International Association for the Study of Pain (IASP)

16. Engeler D, Baranowski AP, Borovicka J, Cottrell A, Dinis-Oliveira P, Elneil S, Hughes J, Messelink EJ, van Ophoven A, Reisman Y, de C Williams AC (2012) EAU Guidelines on 
chronic pelvic pain. http://www.uroweb.org/guidelines/online-guidelines. Accessed 20 October 2015

17. Quintner JL, Bove GM, Cohen ML (2015) A critical evaluation of the trigger point phenomenon. Rheumatology (Oxford) 54 (3):392-399. doi:10.1093/rheumatology/keu471 18. Giamberardino MA, Affaitati G, Fabrizio A, Costantini R (2011) Myofascial pain syndromes and their evaluation. Best Pract Res Clin Rheumatol 25 (2):185-198. doi:10.1016/j.berh.2011.01.002

19. Bump RC, Mattiasson A, Bo K, Brubaker LP, DeLancey JO, Klarskov P, Shull BL, Smith AR (1996) The standardization of terminology of female pelvic organ prolapse and pelvic floor dysfunction. Am J Obstet Gynecol 175 (1):10-17

20. Henry MM, Parks AG, Swash M (1982) The pelvic floor musculature in the descending perineum syndrome. Br J Surg 69 (8):470-472

21. Leiblum S, Bachmann G, Kemmann E, Colburn D, Swartzman L (1983) Vaginal atrophy in the postmenopausal woman. The importance of sexual activity and hormones. JAMA 249 (16):2195-2198

22. Mense S, Simons DG, Russell IJ (2001) Muscle pain : understanding its nature, diagnosis, and treatment. Lippincott Williams \& Wilkins, Philadelphia

23. Simons DG, Mense S (1998) Understanding and measurement of muscle tone as related to clinical muscle pain. Pain 75 (1):1-17

24. Enoka RM (2008) Acute Adjustments. In: Enoka RM (ed) Neuromechanics of human movement. 4th ed. edn. Human Kinetics, Champaign, pp 305-347

25. Masi AT, Hannon JC (2008) Human resting muscle tone (HRMT): narrative introduction and modern concepts. J Bodyw Mov Ther 12 (4):320-332. doi:10.1016/j.jbmt.2008.05.007 26. Nordin M, Frankel VH (2012) Biomechanics of Bone. In: Nordin M, Frankel VH (eds) Basic biomechanics of the musculoskeletal system. 4th ed. edn. Wolters Kluwer/Lippincott Williams \& Wilkins Health, Philadelphia, pp 24-56

27. Gajdosik RL (2001) Passive extensibility of skeletal muscle: review of the literature with clinical implications. Clin Biomech (Bristol, Avon) 16 (2):87-101

28. Mumenthaler M (1992) Neurologic differential diagnosis. Neurologische

Differentialdiagnostik, 2nd ed. edn. Thieme, Stuttgart

29. Preston DC, Shapiro BE (1998) Electromyography and neuromuscular disorders : clinicalelectrophysiologic correlations. Butterworth-Heinemann, Boston

30. Brukner P, Khan KAA (2012) Brukner \& Khan's clinical sports medicine. 4th ed. edn. Mc Graw-Hill, Sydney

31. Gerwin R (2010) Myofascial Pain Syndrome: Here We Are, Where Must We Go? . Journal of Musculoskeletal Pain 18 (4):329-347. doi:10.3109/10582452.2010.502636 32. Lucas N, Macaskill P, Irwig L, Moran R, Bogduk N (2009) Reliability of physical examination for diagnosis of myofascial trigger points: a systematic review of the literature. Clin J Pain 25 (1):80-89. doi:10.1097/AJP.0b013e31817e13b6

33. Dietz HP, Shek C (2008) Validity and reproducibility of the digital detection of levator trauma. Int Urogynecol J Pelvic Floor Dysfunct 19 (8):1097-1101. doi:10.1007/s00192-0080575-1

34. Kruger JA, Dietz HP, Budgett SC, Dumoulin CL (2014) Comparison between transperineal ultrasound and digital detection of levator ani trauma. Can we improve the odds? Neurourol Urodyn 33 (3):307-311. doi:10.1002/nau.22386

35. Kruger J, Dietz P, Botelho C, Dumoulin C (2010) Can we feel with our fingers as well as we see with ultrasound? . Neurourol Urodyn (29):1176-1177.

36. Dietz HP, Hyland G, Hay-Smith J (2006) The assessment of levator trauma: a comparison between palpation and 4D pelvic floor ultrasound. Neurourol Urodyn 25 (5):424-427.

doi:10.1002/nau.20250 
37. Knuttgen HG, Kraemer WJ (1987) Terminology and Measurement in Exercise Performance. The Journal of Strength \& Conditioning Research 1 (1):1-10.

doi:10.1519/00124278-198702000-00001

38. Bo K, Sherburn M (2005) Evaluation of female pelvic-floor muscle function and strength. Phys Ther 85 (3):269-282

39. Howley ET (2001) Type of activity: resistance, aerobic and leisure versus occupational physical activity. Med Sci Sports Exerc 33 (6 Suppl):S364-369; discussion S419-320

40. Komi V (2003) Strength and power in sport. vol v. 3, 2nd ed. edn. Blackwell Science, Osney Mead, Oxford

41. Wilmore JH, Costill DL (1999) Physiology of sport and exercise. 2nd ed. edn. Human Kinetics, Leeds

42. Vodusek DB (2015) Electromyography. In: Bo K, Berghmans B, Morkved S, Van

Kampen M (eds) Evidence-based physical therapy for the pelvic floor : bridging science and clinical practice. Churchill Livingstone, Edinburgh,

43. Knudson D (2007) Fundamentals of Biomechanics : Second Edition. Springer

Science+Business Media, LLC, Boston, MA

44. Sherwood L (2013) Human physiology : from cells to systems. 8th ed. edn. Brooks/Cole, Belmont

45. Kent M (1998) The Oxford dictionary of sports science and medicine. Oxford medical publications, 2nd ed. edn. Oxford University, Oxford

46. Alter MJ (2004) Science of flexibility. 3rd ed. edn. Human Kinetics, Champaign, Ill 47. Møller AR (2011) Intraoperative Neurophysiological Monitoring. 3. edn. Springer New York, New York, NY

48. Dietz HP, Bernardo MJ, Kirby A, Shek KL (2011) Minimal criteria for the diagnosis of avulsion of the puborectalis muscle by tomographic ultrasound. Int Urogynecol J 22 (6):699704. doi:10.1007/s00192-010-1329-4

49. Dietz HP, Abbu A, Shek KL (2008) The levator-urethra gap measurement: a more objective means of determining levator avulsion? Ultrasound Obstet Gynecol 32 (7):941-945. doi:10.1002/uog.6268

50. DeLancey JO, Kearney R, Chou Q, Speights S, Binno S (2003) The appearance of levator ani muscle abnormalities in magnetic resonance images after vaginal delivery. Obstet Gynecol 101 (1):46-53

51. Miller JM, Brandon C, Jacobson JA, Low LK, Zielinski R, Ashton-Miller J, Delancey JO (2010) MRI findings in patients considered high risk for pelvic floor injury studied serially after vaginal childbirth. AJR Am J Roentgenol 195 (3):786-791. doi:10.2214/ajr.09.3508 52. Morgan DM, Umek W, Stein T, Hsu Y, Guire K, DeLancey JO (2007) Interrater reliability of assessing levator ani muscle defects with magnetic resonance images. Int Urogynecol J Pelvic Floor Dysfunct 18 (7):773-778. doi:10.1007/s00192-006-0224-5

53. Berger MB, Morgan DM, DeLancey JO (2014) Levator ani defect scores and pelvic organ prolapse: is there a threshold effect? Int Urogynecol J 25 (10):1375-1379.

doi:10.1007/s00192-014-2388-8

54. Kegel AH (1948) Progressive resistance exercise in the functional restoration of the perineal muscles. Am J Obstet Gynecol 56 (2):238-248

55. Dumoulin C, Bourbonnais D, Lemieux MC (2003) Development of a dynamometer for measuring the isometric force of the pelvic floor musculature. Neurourol Urodyn 22 (7):648653. doi:10.1002/nau.10156

56. Hawker GA, Mian S, Kendzerska T, French M (2011) Measures of adult pain: Visual Analog Scale for Pain (VAS Pain), Numeric Rating Scale for Pain (NRS Pain), McGill Pain Questionnaire (MPQ), Short-Form McGill Pain Questionnaire (SF-MPQ), Chronic Pain Grade Scale (CPGS), Short Form-36 Bodily Pain Scale (SF-36 BPS), and Measure of 
Intermittent and Constant Osteoarthritis Pain (ICOAP). Arthritis Care Res (Hoboken) 63 Suppl 11:S240-252. doi:10.1002/acr.20543

57. Dworkin RH, Turk DC, Wyrwich KW, Beaton D, Cleeland CS, Farrar JT,

Haythornthwaite JA, Jensen MP, Kerns RD, Ader DN, Brandenburg N, Burke LB, Cella D, Chandler J, Cowan P, Dimitrova R, Dionne R, Hertz S, Jadad AR, Katz NP, Kehlet H,

Kramer LD, Manning DC, McCormick C, McDermott MP, McQuay HJ, Patel S, Porter L, Quessy S, Rappaport BA, Rauschkolb C, Revicki DA, Rothman M, Schmader KE, Stacey BR, Stauffer JW, von Stein T, White RE, Witter J, Zavisic S (2008) Interpreting the clinical importance of treatment outcomes in chronic pain clinical trials: IMMPACT recommendations. J Pain 9 (2):105-121. doi:10.1016/j.jpain.2007.09.005

58. Droz J, Howard FM (2011) Use of the Short-Form McGill Pain Questionnaire as a diagnostic tool in women with chronic pelvic pain. J Minim Invasive Gynecol 18 (2):211-217. doi:10.1016/j.jmig.2010.12.009

59. Barber MD, Chen Z, Lukacz E, Markland A, Wai C, Brubaker L, Nygaard I, Weidner A, Janz NK, Spino C (2011) Further validation of the short form versions of the Pelvic Floor Distress Inventory (PFDI) and Pelvic Floor Impact Questionnaire (PFIQ). Neurourol Urodyn 30 (4):541-546. doi:10.1002/nau.20934

60. Gerstenberger EP, Rosen RC, Brewer JV, Meston CM, Brotto LA, Wiegel M, Sand M (2010) Sexual Desire and the Female Sexual Function Index (FSFI): a sexual desire cutpoint for clinical interpretation of the FSFI in women with and without hypoactive sexual desire disorder. J Sex Med 7 (9):3096-3103. doi:10.1111/j.1743-6109.2010.01871.x

61. Derogatis LR, Rosen R, Leiblum S, Burnett A, Heiman J (2002) The Female Sexual Distress Scale (FSDS): initial validation of a standardized scale for assessment of sexually related personal distress in women. J Sex Marital Ther 28 (4):317-330

62. Quaghebeur J, Wyndaele JJ (2013) Comparison of questionnaires used for the evaluation of patients with chronic pelvic pain. Neurourol Urodyn 32 (8):1074-1079.

doi:10.1002/nau.22364

63. Boddy Mapping. Public and Commercial Services Union.

http://www.pcs.org.uk/en/resources/health_and_safety/health_and_safety_reps_toolkit/bodymapping.cfm. Accessed 20. October 2015

64. The free dictionary http://medical-dictionary.thefreedictionary.com Accessed 20 October 2015

65. Oxford Learner's Dictionarie. http://www.oxfordlearnersdictionaries.com. Accessed 14 November 2015

66. Policy statement: Description of physical therapy. World Confederation for Physical Therapy (WCPT). http://www.wcpt.org/policy/ps-descriptionPT. Accessed 29. November 2015

67. Adherence to long-term therapies: evidence for action. (2003). World Health Organization,

68. Nunes V, Neilson J, O’Flynn N, Calvert N, Kuntze S, Smithson H, Benson J, Blair J, Bowser A, Clyne W, Crome P, Haddad P, Hemingway S, Horne R, Johnson S, Kelly S, Packham B, Patel M, Steel J (2009) Clinical Guidelines and Evidence Review for Medicines Adherence: involving patients in decisions about prescribed medicines and supporting adherence. National Collaborating Centre for Primary Care and Royal College of General Practitioners, London

69. Friedlander JI, Shorter B, Moldwin RM (2012) Diet and its role in interstitial cystitis/bladder pain syndrome (IC/BPS) and comorbid conditions. BJU Int 109 (11):15841591. doi:10.1111/j.1464-410X.2011.10860.x

70. Shorter B, Lesser M, Moldwin RM, Kushner L (2007) Effect of comestibles on symptoms of interstitial cystitis. J Urol 178 (1):145-152. doi:10.1016/j.juro.2007.03.020 
71. Moore K, Dumoulin C, C. B, Burgio K, Chambers T, Hagen S, Hunter K, Imamura M, Thakar R, Williams K, Vale L (2013) Adult conservative management. Incontinence 5th International Consultation on Incontinence Paris February, 2012

72. Bouchard C, Shephard RJ, Stephens T (1993) Physical activity, fitness, and health : consensus statement. Human Kinetics, Champaign, Ill

73. Meijlink JM (2013) A Patient Perspective. In: Nordling J, J. WJ, Van de Merwe JP, Bouchelouche P, Cervigni M, Fall M (eds) Bladder Pain Syndrome: A Guide for Clinicans. Springer Science + Business Media, New York. doi:10.1007/978-1-4419-6929-3_1

74. Rollnick S, Miller WR (1995) What is motivational interviewing? . Behavioural and Cognitive Psychotherapy 23 (04):325-334. doi:10.1017/S135246580001643X

75. Bandura A (1977) Self-efficacy: toward a unifying theory of behavioral change. Psychol Rev 84 (2):191-215

76. Wyman JF, Burgio KL, Newman DK (2009) Practical aspects of lifestyle modifications and behavioural interventions in the treatment of overactive bladder and urgency urinary incontinence. Int J Clin Pract 63 (8):1177-1191. doi:10.1111/j.1742-1241.2009.02078.x 77. Chiarelli P, Markwell S (1992) Let's get things moving. Gore and Osment, Sydney 78. Markwell S, Sapsford R (1998) Physiotherapy management of pelvic floor dysfunction. In: Sapsford R, S. Markwell S, Bullock-Saxton J (eds) Women's Health: A Textbook for Physiotherapists. WB Saunders Company Ltd, London, pp 383-407

79. Norton C, Whitehead WE, Bliss DZ, Harari D, Lang J (2010) Management of fecal incontinence in adults. Neurourol Urodyn 29 (1):199-206. doi:10.1002/nau.20803

80. NICE Faecal incontinence: The management of faecal incontinence in adults. NICE clinical guideline 49 (June 2007: 6.). http://www.nice.org.uk/guidance/cg49/evidence/fullguideline-195116653.

81. The National Institute of Diabetes and Digestive and Kidney Diseases (NIDDK) National Institute for Health (NIH).

http://digestive.niddk.nih.gov/ddiseases/pubs/fecalincontinence/Fecal_Incontinence_508.pdf. Accessed 20 November 2015

82. Kraemer WJ, Häkkinen K (2002) Strength training for sport. Handbook of sports medicine and science. Blackwell Science, Oxford

83. American College of Sports Medicine position stand. Progression models in resistance training for healthy adults (2009). Med Sci Sports Exerc 41 (3):687-708.

doi:10.1249/MSS.0b013e3181915670

84. Fleck SJ, Kraemer WJ (2004) Designing resistance training programs. 3rd edn. Human Kinetics, Champaign, IL

85. Tortora GJ, Derrickson B (2009) Principles of anatomy and physiology. 12th edn. Wiley, New York

86. Bo K, Hagen RH, Kvarstein B, Jørgensen J, Larsen S, Burgio KL (1990) Pelvic floor muscle exercise for the treatment of female stress urinary incontinence:III.Effects of two different degrees of pelvic floor muscle exercises Neurourol and Urodyn 9 (5):489-502. doi:10.1002/nau.1930090505

87. Plevnik S (1985) A new method for testing and strengthening pelvic floor muscle In: Proceedings of the International Continence Society. pp 267-268

88. Coville CA (1979) Relaxation in physical education curricula. Physical Educator 36

(4):176-181

89. Jacobson E (1938) Progressive relaxation. University of Chicago Press, Chicago:

90. Astin (2000) Meditation. In: Novey D (ed) Clinician's complete reference to complementary and alternative medicine. Mosby, St.Louis, 
91. Baer RA (2003) Mindfulness Training as a Clinical Intervention: A Conceptual and Empirical Review. Clinical Psychology: Science and Practice 10 (2):125-143.

doi:10.1093/clipsy.bpg015

92. Shumway-Cook A, Woollacott MH (1995) Motor control : theory and practical

applications. Williams \& Wilkins, Baltimore

93. Schwartz GE, Beatty J (1977) Biofeedback, theory and research. Academic Press, New

York

94. Bo K, Berghmans B, Morkved S, Van Kampen M (2015) Evidence-based physical

therapy for the pelvic floor : bridging science and clinical practice. 2 nd edn. Churchill

Livingstone, Edinburgh

95. Cram JR, Kasman GS, Holtz J (1998) Introduction to surface electromyography. Aspen

Publishers, Gaithersburg

96. Schwartz MS, Andrasik F (2003) Biofeedback : a practitioner's guide. 3rd edn. Guilford

Press, New York

97. Haslam J, Mantle J (2004) Bowel and anorectal function and dysfunction. In: Mantle J,

Haslam J, Barton S (eds) Physiotherapy in Obstetrics and Gynaecology. 2nd edn.

Butterworth-Heinemann, London, pp 417-420

98. Beckmann MM, Stock OM (2013) Antenatal perineal massage for reducing perineal trauma. Cochrane Database Syst Rev 4:CD005123. doi:10.1002/14651858.CD005123.pub3

99. Cyriax JH, Cyriax PJ (1998) Cyriax's llustrated Manual of Orthopedic Medicine. 2nd edn. Butterworth Heinemann, Oxford UK.

100. Thiele GH (1936) Tonic spasm of the levator ani, coccygeus and piriformis muscles.

Trans Am Proct Soc 37:145-155

101. Robinson AJ, Snyder-Mackler L (2007) Clinical Electrophysiology : Electrotherapy and electrophysiologic testing. 3nd ed. edn. Lippincott Williams \& Wilkins, Baltimore

102. Schreiner L, Santos TG, Souza AB, Nygaard CC, Silva Filho IG (2013) Electrical

stimulation for urinary incontinence in women: a systematic review. Int Braz J Urol 39

(4):454-464. doi:10.1590/s1677-5538.ibju.2013.04.02

103. Berghmans B, van Waalwijk van Doorn E, Nieman F, de Bie R, van den Brandt P, Van

Kerrebroeck P (2002) Efficacy of physical therapeutic modalities in women with proven

bladder overactivity. Eur Urol 41 (6):581-587

104. Jabs CF, Stanton SL (2001) Urge incontinence and detrusor instability. Int Urogynecol J

Pelvic Floor Dysfunct 12 (1):58-68

105. Eriksen BC, Eik-Nes SH (1989) Long-term electrostimulation of the pelvic floor:

primary therapy in female stress incontinence? Urol Int 44 (2):90-95

106. Yamanishi T, Yasuda K, Sakakibara R, Hattori T, Ito H, Murakami S (1997) Pelvic floor electrical stimulation in the treatment of stress incontinence: an investigational study and a placebo controlled double-blind trial. J Urol 158 (6):2127-2131

107. Yamanishi T, Sakakibara R, Uchiyama T, Suda S, Hattori T, Ito H, Yasuda K (2000)

Comparative study of the effects of magnetic versus electrical stimulation on inhibition of detrusor overactivity. Urology 56 (5):777-781

108. Yamanishi T, Yasuda K, Sakakibara R, Hattori T, Suda S (2000) Randomized, doubleblind study of electrical stimulation for urinary incontinence due to detrusor overactivity.

Urology 55 (3):353-357

109. Govier FE, Litwiller S, Nitti V, Kreder KJ, Jr., Rosenblatt P (2001) Percutaneous

afferent neuromodulation for the refractory overactive bladder: results of a multicenter study. J Urol 165 (4):1193-1198

110. Janknegt RA, Weil EH, Eerdmans PH (1997) Improving neuromodulation technique for refractory voiding dysfunctions: two-stage implant. Urology 49 (3):358-362.

doi:10.1016/s0090-4295(96)00506-7 
111. van Balken MR, Vandoninck V, Gisolf KW, Vergunst H, Kiemeney LA, Debruyne FM, Bemelmans BL (2001) Posterior tibial nerve stimulation as neuromodulative treatment of lower urinary tract dysfunction. J Urol 166 (3):914-918

112. Belanger A-Y (2010) Therapeutic Electrophysical Agents: Evidence Behind Practice. 2nd edn. Lippincott Williams \& Wilkins, Philadelphia

113. Electrotherapeutic Terminology in Physical Therapy. (2000) American Physical Therapy Association (APTA).

https://iweb.apta.org/Purchase/ProductDetail.aspx?Product_code=P-72. Accessed 20 November 2015

114. Cottenden A, Bliss D, Buckley B, Fader M, Gartley C, Hayder D, Ostaszkiewicz J, Wilde M (2013) Management using continence products. In: Abrams P, Cardozo L, Khoury $\mathrm{S}$, Wein A (eds): Incontinence. 5th International Consultation on Incontinence. Paris, Feb 2012. Committee 20: 1651-1786. European Association of Urology/ ICUD 2013. ISBN: 9789953-493-21-3.

115. Deutekom M, Dobben AC (2012) Plugs for containing faecal incontinence. Cochrane Database Syst Rev 4:CD005086. doi:10.1002/14651858.CD005086.pub3

116. Webster's New World Dictionary (2008). 3rd edn. Wiley Publishing Incorporated, 117. Lipp A, Shaw C, Glavind K (2011) Mechanical devices for urinary incontinence in women. Cochrane Database Syst Rev (7):CD001756. doi:10.1002/14651858.CD001756.pub5 118. Adams E, Thomson A, Maher C, Hagen S (2004) Mechanical devices for pelvic organ prolapse in women. Cochrane Database Syst Rev (2):CD004010.

doi:10.1002/14651858.CD004010.pub2

119. Oliver R, Thakar R, Sultan AH (2011) The history and usage of the vaginal pessary: a review. Eur J Obstet Gynecol Reprod Biol 156 (2):125-130. doi:10.1016/j.ejogrb.2010.12.039 120. Urinary tract infection in women -self-care. MedlinePlus http://www.nlm.nih.gov/medlineplus/ency/patientinstructions/000391.htm. Accessed 20 November 2015 121. Epp A, Larochelle A, Lovatsis D, Walter JE, Easton W, Farrell SA, Girouard L, Gupta C, Harvey MA, Robert M, Ross S, Schachter J, Schulz JA, Wilkie D, Ehman W, Domb S, Gagnon A, Hughes O, Konkin J, Lynch J, Marshall C (2010) Recurrent urinary tract infection. J Obstet Gynaecol Can 32 (11):1082-1101

122. National Vulvodynia Association. http://www.nva.org. Accessed 20 October 2015 123. Braunstein S, van de Wijgert J (2005) Preferences and practices related to vaginal lubrication: implications for microbicide acceptability and clinical testing. J Womens Health (Larchmt) 14 (5):424-433. doi:10.1089/jwh.2005.14.424

124. . http://www.nevdgp.org.au/info/incontinence/i_aids.htm] Accessed 10 October 2015 125. Schumm K, Lam TB (2008) Types of urethral catheters for management of short-term voiding problems in hospitalised adults. Cochrane Database Syst Rev (2):CD004013. doi:10.1002/14651858.CD004013.pub1

126. Logan K, Shaw C, Webber I, Samuel S, Broome L (2008) Patients' experiences of learning clean intermittent self-catheterization: a qualitative study. J Adv Nurs 62 (1):32-40. doi:10.1111/j.1365-2648.2007.04536.x

127. Shaw C, Logan K, Webber I, Broome L, Samuel S (2008) Effect of clean intermittent self-catheterization on quality of life: a qualitative study. J Adv Nurs 61 (6):641-650. doi:10.1111/j.1365-2648.2007.04556.x 128. Clinical Practice Guidelines Adult Clean Intermittent Catheterization. SUNA, Society of Urologic Nurses and Associates http://www.suna.org/resources/adultCICGuide.pdf. Accessed 20 October 2015 


\section{FIGURE LEGENDS}

Figure 1: Levator hiatal dimensions measured using trans-perineal ultrasound (with permission from Ingeborg Hoff Braekken)

Figure 2: Digital palpation of the pelvic floor muscles (with permission from subjects in photo and photographer Andreas Birger Johansen)

Figure 3: Peritron manometer (with permission from Laborie)

Figure 4: Graphical illustration of pelvic floor muscle manometry readings (with permission from illustrator Ingeborg Hoff Braekken)

Figure 5: Ann Arbor, USA Dynamometer speculum. Note that the bills of the speculum are covered by a condom in actual use (with permission from Ashton-Miller JA, Zielinski R, DeLancey JO, Miller JM.)

Figure 6: Montreal, Canada, Dynamometer apparatus (with permission from Chantale Dumoulin)

Figure 7: Verity Medical NeuroTrac Myoplus Pro surface EMG biofeedback apparatus (also incorporating electrical stimulation (with permission from Quintet, Norway)

Figure 8: Patient education of pelvic floor muscle function (with permission from Women's and Men's Health Physiotherapy) 
Figure 9: Enraf-Nonius Myomed pelvic floor machine, including electrical stimulation (with permission from Enraf-Nonius). 